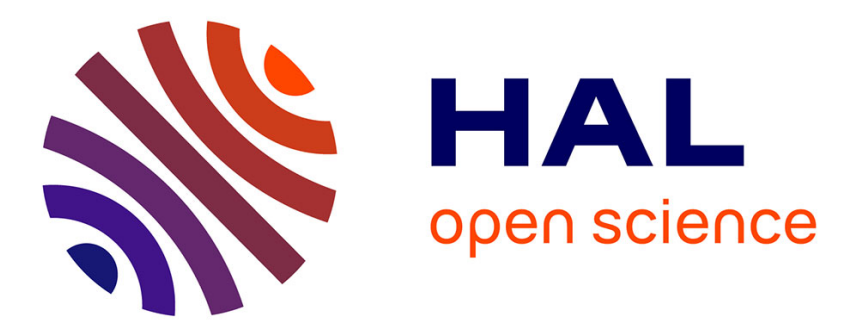

\title{
MS-based targeted metabolomics of eicosanoids and other oxylipins: Analytical and inter-individual variabilities
}

Cécile Gladine, A. I. Ostermann, J. W. Newman, N. H. Schebb

\section{To cite this version:}

Cécile Gladine, A. I. Ostermann, J. W. Newman, N. H. Schebb. MS-based targeted metabolomics of eicosanoids and other oxylipins: Analytical and inter-individual variabilities. Free Radical Biology and Medicine, 2019, 144 (SI), 10.1016/j.freeradbiomed.2019.05.012 • hal-02154450

\author{
HAL Id: hal-02154450 \\ https://hal.science/hal-02154450
}

Submitted on 3 Dec 2019

HAL is a multi-disciplinary open access archive for the deposit and dissemination of scientific research documents, whether they are published or not. The documents may come from teaching and research institutions in France or abroad, or from public or private research centers.
L'archive ouverte pluridisciplinaire $\mathbf{H A L}$, est destinée au dépôt et à la diffusion de documents scientifiques de niveau recherche, publiés ou non, émanant des établissements d'enseignement et de recherche français ou étrangers, des laboratoires publics ou privés. 
MS-based targeted metabolomics of eicosanoids and other oxylipins: analytical and inter-

\author{
individual variabilities.
}

3

${ }^{1}$ Université Clermont Auvergne, INRA, UNH, Unité de Nutrition Humaine, CRNH Auvergne, Clermont-

Ferrand, France.

${ }^{2}$ Chair of Food Chemistry, Faculty of Mathematics and Natural Sciences, Gaußstraße 20, University of

Wuppertal, 42119, Wuppertal Germany

${ }^{3}$ United States Department of Agriculture, Agricultural Researh Service, Western Human Nutrition

\footnotetext{
${ }^{1}$ Abbreviations: (U)HPLC-MS, (ultra) high performance liquid chromatography-mass spectrometry ; AA, arachidonic acid; PUFAs, polyunsaturated fatty acids; COX, cycloxygenase; PG, prostaglandin; $T$, thromboxanes; LOX, lipoxygenase; LT, leukotrienes; CYP, cytochrome P450 ; EPA, eicosapentaenoic acid ; GPCR, G protein-coupled receptor ; TRPs, transient receptor potential channels ; PPARs, peroxisome proliferator-activated receptors ; NFKB, nuclear factor kappa B ; DHA, docosahexaenoic acid ; EpOME, epoxyoctadecenoic acid; HODE, hydroxyoctadecadienoic acid; KODE, ketooctadecadienoic acid ; CRP, Creactive protein ; HETE, hydroxyeicosatetraenoic acid ; HEPE, hydroxyeicosapentaenoic acid ; HDHA, hydroxydocosahexaenoic acid ; EDTA, ethylenediaminetetraacetic acid ; TriHOME, trihydroxyoctadecenoic acid ; BHT, butylated hydroxytoluene ; SPE, solid phase extraction ; ESI-MS, electrospray ionization-mass spectrometry ; GLC-MS, gas liquid chromatography mass spectrometry; QqQ-MS, triple quadrupole mass spectrometry ; TOF, time of flight ; EpETrE, epoxyeicosatrienoic acid ; SPM, specialized pro-resolving mediators ; LX, lipoxin ; MaR, maresin ; PD, protectin ; LLOQ, lower limit of quantification ; LOD, limit of detection ; HMGCoA, 3-Hydroxy-3-Methyl-Glutaryl-CoA reductase ; FLAP, 5-lipoxygenase-activating protein ; CVD, cardiovascular diseases ; SEH, soluble epoxyhydroalse ; CAD, coronary artery diseases.
} 
Abstract (150 words).

15

Oxylipins, including the well-known eicosanoids, are potent lipid mediators involved in numerous physiological and pathological processes. Therefore, their quantitative profiling has gained a lot of attention during the last years notably in the active field of health biomarker discovery. Oxylipins include hundreds of structurally and stereochemically distinct lipid species which today are most commonly analyzed by (ultra) high performance liquid chromatography-mass spectrometry based ((U)HPLC-MS) methods. To maximize the utility of oxylipin profiling in clinical research, it is crucial to understand and assess the factors contributing to the analytical and biological variability of oxylipin profiles in humans. In this review, these factors and their impacts are summarized and discussed, providing a framework for recommendations expected to enhance the interlaboratory comparability and biological interpretation of oxylipin profiling in clinical research. 


\section{Introduction.}

Eicosanoids and other oxylipins represent a superfamily of signalling lipids generated from arachidonic acid (AA) and related polyunsaturated fatty acids (PUFAs) through a complex network of biochemical reactions involving over 50 unique and cell-specific enzymes (1). To regulate a wide array of biological processes, PUFAs are converted to oxylipins via four major pathways (Figure 1): the cyclooxygenase (COX) pathway producing prostanoids such as prostaglandins (PG) and thromboxanes (Tx); the lipoxygenase (LOX) pathway producing hydroperoxy-PUFAs which are rearranged into monohydroxy-PUFAs or further converted by LOX catalyzed reactions to leukotrienes (LT) and numerous dihydroxy- and trihydroxy-PUFAs, including specialized pro-resolving mediators (e.g. lipoxins, resolvins, protectins); the cytochrome P450 pathway (CYP), primarily producing $\omega-/ \omega-1$ hydroxy- and epoxy-PUFAs, with the epoxides being further transformed to vicinal (i.e. adjacent or 1,2-)dihydroxy-PUFAs; and the nonenzymatic pathway producing various hydro(peroxy) PUFAs, epoxy-PUFAs (2) as well as iso- and neuroprostanes $(3,4)$. In response to external stimuli (e.g. bradykinin, thrombin, inflammatory insult), PUFAs (5) and oxylipins (6) are released from membrane phospholipids by phospholipases including phospholipase A2 (PLA2). Of note, hundreds of structurally and strereochemically distinct oxylipins can be produced from AA and other PUFAs. For instance, depending on the stimuli and the cell type, AA and EPA can be converted into $\mathrm{PGE}_{2}$ and $\mathrm{PGE}_{3}$ respectiveley through the COX pathway or structurally distinct oxylipins (e.g. $\mathrm{LTB}_{4}$ and $\mathrm{LTB}_{5}$ ) via the 5-LOX pathway (Figure 1).

The structural specificity of oxylipins leads to specificity in their biological activities, many of which are still being elucidated. Important to clinical research, they are notably involved in the regulation of inflammation, thrombosis, endothelial function, vascular tone and insulin secretion, each of these systems being either stimulated or inhibited by the different oxylipin types as simplified in Figure 2. Many oxylipins exert their biological effects by binding to cognate receptors, which are members of the G protein-coupled receptor (GPCR). However, for several oxylipins such as 
epoxy-PUFAs, the receptors characterized to date cannot explain all of the biological effects elicited by these compounds (7). Other known routes of oxylipin elicited effects include directly influencing the open-state probability of membrane ion channels including the calcium sensitive potassium channels $\left(\mathrm{K}_{\mathrm{Ca}}\right)$ and transient receptor potential channels (TRPs) (8-10), activation of intracellular transcription factors such as PPARs $(11,12)$, and interference with intracellular signalling pathways such as NFKB (13-15).

Oxylipins derived from omega-3 fatty acids can be either more or less potent than or antagonistic to their omega-6-derived analogs (16), e.g epoxy-omega-3-PUFA are more potent antihypertensive compounds than their arachidonic acid-derived counterparts (17). Even two oxylipins derived from the same PUFA can be antogonists. For instance, $\mathrm{TxA}_{2}$ and $\mathrm{PG} \mathrm{I}_{2}$, both derived from the oxygenation of AA through the COX-dependent metabolism, respectively activate or inhibit thrombosis. Such regulatory cross talk among metabolic cascades is common (18-20). Finally, depending on the receptor, the tissue or the dose, a single oxylipin can also have opposite effects. For example, $\mathrm{PGE}_{2}$ can exert either pro- or anti-aggregatory effects depending on its dose or the type of EP receptor it binds to (21). Similarly, $\mathrm{PGE}_{2}$ mediates lung inflammation in human cells (22) whereas it inhibits inflammatory signalling in murine peritoneal macrophages (23). Moreover, while $\mathrm{PGD}_{2}$ synthesis can have both pro- and anti-inflammatory impacts, and is synthesized by two convergent gene products (24), regulation of this system controls the onset and resolution of inflammation in some models (25).

While oxylipins are found in all tissues, cells are highly selective as to the type of oxylipin they synthesize. For instance, $\mathrm{TxA}_{2}$ is mainly produced by platelets, while the endothelium is a major source of $\mathrm{PGI}_{2}$. Of note, TxA synthase is also expressed in lung and macrophages and significant levels of PGI synthase is found in smooth muscle cells $(26,27)$. $\mathrm{PGF}_{2} \alpha$ is mainly produced by uterus, $\mathrm{PGE}_{2}$ is the major oxylipin generated in kidney (5) and skin (28), and the hematopeietic form of PGD synthases is highly expressed in immune and inflammatory cells, but also identified in brain and 
ovary $(24,29)$. Some LOXs also have preferential cell distribution with LOX-5 being mainly expressed in leukocytes, macrophages and dendritic cells 12/15-LOX (ALOX15) has a broad tissue distribution (30) but is notably abundant in eosinophils and bronchial epithelium, 15-LOX2 (ALOX15B) is highly expressed in the skin and prostate, while 12-LOX (ALOX12) is mainly found in platelets (31). Interestingly the regiospecificity of products from a single enzyme can differ for unique PUFAs. For example while 15-LOX yields the 15-hydroperoxy metabolite of AA, it produces similar amounts of 14- and 17-hydroperoxy metabolites of DHA (32). While CYPs are highly expressed in liver, there are also high levels of expression in brain, lungs, kidneys, gastro-intestinal tract and heart (33). Humans express $\sim 50 \mathrm{CYP}$ isoforms, 20 of which are shown to biosynthesize oxylipins, notably members of the CYP2C (e.g. CYP2C8, CYP2C9, CYP2C19) and CYP2J (e.g. CYP2J2) families that are the predominant human epoxygenases, while CYP4A and CYP4F have predominantly $\omega / \omega$-1-hydrolase activity (34). In plasma, the major part of hydroxy-PUFA and epoxy-PUFA are found esterified into lipids (35), e.g. the glycerolipids of lipoproteins (> 95\% in rats) (36). Other vectors of circulating oxylipins include albumin that can both passively adsorb oxylipins (37) or form covalent adducts (38) and extracellular vesicles that are both carriers and producers of oxylipins (39). Free oxylipins are also detected in plasma and are dramatically influenced postprandially by the nature of the diet $(40,41)$.

Oxylipin profiling has the potential to provide a wealth of information regarding global changes in the homeostasis of a vast array of biological processes. Current MS-based oxylipin targeted metabolomics allows the assessment of changes in a vast array of oxylipins simultaneously within acceptable run-times, resulting in increased interest in oxylipin profiling during recent years, notably in the active field of biomarker discovery. This review will present applications of oxylipin profiling over the past several years, while describing the main analytical and biological factors contributing to the variability in oxylipin profiles.

\section{Applications of the MS-Based profiling of oxylipins.}


The synthesis of oxylipins and subsequent induction of cell signalling pathways is tightly regulated under normal physiological conditions. Oxylipin synthesizing enzymes and/or receptor dysregulation is associated with a variety of diseases including cardiovascular diseases (CVD) and various immune-related diseases. Moreover, the manipulation of oxylipin synthesis, through modulation of precursor PUFAs or enzyme inhibitors via nutritional or therapeutic approaches, has great potential in the prevention and management of disease. Therefore, oxylipin profiling of biological fluids is being used to identify potential disease biomarkers, to characterize inflammatory and oxidative status, and to monitor the effects of nutrition or drugs on these regulatory systems. Recent studies addressing one of these goals are presented in Table 1.

Of note, the study design (i.e. power, participant selection and matching), the analytical choices (free or total, plasma or serum), and the metabolic coverage of the MS-method applied (number and variety of oxylipins) are very different between the studies and more importantly these parameters may have significant consequences on the relevance and robustness of the biomarkers identified. While the natural variance and reference value of oxylipin levels in healthy humans is not clinically established, recent results show that the mean coeifficient of variation (CV) of oxylipins in the plasma of clinically healthy human can reach $87 \%$ and the magnitude of variance depends on the type and concentration of oxylipin considered (42) (Figure 3). This high variance highlights the need for large clinical cohorts of well-selected and matched participants to properly power studies to identify discriminant oxylipins. However, while the absolute concentration of individual oxylipins is likely important, shifts in oxylipin relative abundance or pattern may hold great potential as complex disease biomarkers. Therefore, as assays increase their metabolic coverage of representative oxylipins, they will provide a higher resolution pattern to be considered for biomarker discovery.

In the field of disease biomarkers, most studies applying oxylipin profiling are related to cardiometabolic disorders. For instance, in a recent nested case-control cohort study involving 175 
insulin use, statin use, and smoking) and covering 36 free oxylipins, one factor containing 10 free fatty acids and 19 oxylipins was significantly associated with cardiovascular events (42). Of note, this association was only observed in non-diabetic patients highlighting the need for patient stratification in clinical investigation. Moreover, linoleic-acid derived epoxides, alcohols and ketones (i.e. EpOMEs, 9HODE, 13-HODE and 13-KODE) were the metabolites most strongly associated with change in interadventitia common carotid artery diameter over time. In a Chinese population, a large nested casecontrol cohort study involving 744 incident acute myocardial infarction cases and 744 controls matched for gender, dialect group, date of birth, date of recruitment and date of blood collection failed to detect significant association between free oxylipin clusters and acute myocardial infarction (besides $\mathrm{TXB}_{2}$ which may reflect sample collection, processing or storage) (43). Interestingly, the authors suggested that examining oxylipins within the esterified pool of lipoprotein particules rather than free oxylipins could provide better predictive biomarkers of coronary heart disease. This lays emphasis on this critical point when focusing on oxylipins as potential disease biomarkers. Although the origin and role of most free and almost all esterified oxylipins are not well understood, assessing the esterified pool could be more relevant in a context of biomarker discovery for three main reasons: (i) it represents the major portion of circulating oxylipins (especially epoxy- and hydroxyPUFA); (ii) it is known to be biologically active (44); and (iii) it fluctuates as a function of lipoprotein particle concentrations and composition (45), which is of importance since other factors associated with such lipidomic fluctuations are known disease risk factors (e.g. hypertriglyceridemia, cholesterol distributions). Moreover, one can expect (whereas this has not been assessed) that the esterified oxylipins are more stable and therefore less affected by sample collection, processing or storage.

Another common application for the targeted metabolomics of oxylipins is to generate an integrative assessment of the inflammatory and oxidative stress status of an individual. The utility of such data is also enhanced by broad metabolic coverage to include complementary and opposing oxylipins derived from all pathways and multiple substrates to allow relevant biological interpretation. Inflammation and oxidative stress are the drivers for the onset of many diseases and 
assessing them accurately is therefore crucial in clinical research. Inflammatory status is usually quantified by markers like C-reactive protein (CRP), interleukin 1, TNF- $\alpha$, and fibrinogen while the non-enzymatically formed isoprostanes are considered to be the "gold standard" biomarkers of endogenous lipid peroxidation and oxidative stress (46). However, we recently observed in patients in the early phases of sarcopenia that the classic inflammatory biomarkers do not identify subtle differences in inflammatory and oxidative stress status (47). Indeed, although CRP and $\mathrm{F}_{2^{-}}$ isoprostanes were similar in patients with different muscle status, several oxylipins (e.g. 15-HETE, 5HEPE, 9-HETE, 9-HEPE and 14-HDHA) demonstrated subtle differences in inflammation and oxidative stress providing a better characterization of the early phases of sarcopenia.

Targeted metabolomics of circulating oxylipins has also been widely used to monitor and subsequently understand the effect of diet (mainly omega-3 fatty acids) or drugs (e.g. antiinflammatory drugs) on health. The impacts of these two environmental factors on oxylipin patterns will be detailed later (see section 4.1), but important observations arised from studies presented in Table 1. The first is related to the variability of response which is systematicaly reported by the authors, depending for example on the basal status of omega-3 fatty acids $(48,49)$, participant health status (45), age and sex (50). The second observation refers to the necessity to assess all pathways of oxylipin biosynthesis to identifiy unexpected effects of treatments (51). As with the influence of basal omega-3 fatty acid status on oxylipin responses to fish oil consumption (52), examination of response dynamics through the use of regression analysis can actually take advantage of such variance to provide new information. Similarly, if unique response phenotypes are observed within an experimental population, it may be important to develop new hypotheses surrounding the associations of oxylipins and health risks to truely understand the utility of these potential biomarkers in clinical research.

MS-based targeted metabolomics of oxylipins represents a very interesting tool for various applications in clinical research, but the impact of analytical and biological parameters on the 
variability of oxylipin patterns needs further understanding to avoid inappropriate study design and subsequent biased biological interpretation. Moreover, expansive oxylipin coverage will increase our ability to interpret the interactions and cross-talk among the various biosynthetic routes and substratedependent metabolites, informing our understanding and possible treatment of dysoxylipinemic diseases.

\section{Analytical variability linked to the MS-based profiling of circulating oxylipins.}

To enhance our understanding of the physiological roles of oxylipins that influence health and disease, high quality data are required from a wide array of biological matrices. Therefore, robust analytical methods with high sensitivity, accuracy and precision, are needed. Due to the complex and interactive nature of lipid mediator signaling, it is now well accepted that the physiological effects of these compounds result from a shift in the overall oxylipin pattern, e.g. from a pro- to an antiinflammatory status (53), rather than from the absolute concentration of individual mediators. Thus, state-of-the-art analytical methods aim to precisely detect as many members of the oxylipin cascades

The analysis of oxylipins as a superclass of endogenous compounds presents a number of challenges including a diverse array of compound polarity, stability, and endogenous concentrations that can vary $\geq 4$-orders of magnitude $(55,56)$. Therefore, to quantify oxylipins with high sensitivity and precision, critical considerations include sample collection and storage, instrument selection, analytical breadth and the biological matrix of concern. Each of these factors will affect method development aspects such as the modes of analyte extraction.

3.1 Sample collection procedures - A major source of variability in analysis is the formation/degradation of oxylipins during or after sample collection. Oxylipins, particularly COX-1 derived Tx as well as 12-LOX generated hydro(peroxy)-PUFA are formed during blood coagulation 
time and temperature for coagulation before spinning and freezing affects the formation of oxylipins (59). The anticoagulant - e.g. ethylenediaminetetraacetic acid (EDTA) or heparin - used for the preparation of plasma has also been shown to modulate the oxylipin pattern $(57,60,61)$. Thus, levels between differently generated plasmas may vary considerably and should not be directly compared. EDTA is used in most studies investigating the oxylipin profile (Table 1). Best practice is to centrifuge and store samples immediately after collection and define minimal/maximal duration and conditions for transitory storage. Even short periods of storage (1-2 h) of plasma at room temperature or in the refrigerator lead to ex vivo changes in the oxylipin profiles $(57,60)$. For example, Figure 4 shows the massive variability induced by differences in the handling of whole blood during the first two hours post-blood collection at different temperatures prior to plasma isolation. Although the direct addition of methanol $(57,60)$ or additives (inhibitors or antioxidants) might have beneficial effects on the stability of analytes. However, these procedures are seldom feasible in clinical settings, since commercially available collection tubes containing such materials are not currently available. Similar considerations are needed in the standardization of post-coagulation freezing delays when serum analyses are considered experimentally relevant (59). Serial sampling from indwelling catheters offers unique challenges, and the process of catheter maintenance must be carefully chosen. If heparin is used for catheter maintenance, or in association with other medical interventions (e.g. heart lung machine action) large increases in circulating non-esterified oxylipins are observed (61, $62,63)$. Although heparin stabilization of lipoprotein lipase can be reversed by the administration of protamine sulfate, great care should be taken when analyzing and interpreting such samples due to the effect heparin can have on the oxylipin profile in these settings.

These data illustrate the importance of standardized procedures and protocols in clinical studies to reduce sample collection induced variability in oxylipin concentrations. Regardless, the analysis of blood samples from cohort studies collected with non-documented and/or variable sample conditions may be valuable to help define the physiological role of oxylipins. However, researchers should consider that such data sets may have higher than expected variance and 
carefully consider interpretation of data pertaining to metabolites with known instabilities. If future studies can identify robust markers of poor sample handling, these may provide non-biased tools for the exclusion of samples with evidence of significant ex-vivo changes in oxylipin profiles, increasing the utility of such studies. In at least 3 studies to date we have found that greatly exaggerated concentrations of 9-HETE and the linoleate-derived trihydroxy metabolites (TriHOMEs) may be such potential markers of poor sample handling (unpublished data). Moreover, in order to correctly interpret the results, quantitative data on the variability induced by transitory storage at each step of plasma generation prior storage at $-80^{\circ} \mathrm{C}$ is urgently needed.

3.2 Sample storage procedures - Variability of oxylipin levels is also induced by storage time and conditions. In a recent article, Giera and coworkers show an impressive data set demonstrating that only 4 weeks storage at $-20^{\circ} \mathrm{C}$ leads to artificial oxylipin formation (57). This is consistent with earlier reports showing that short term storage at $4^{\circ} \mathrm{C}$ as well as freeze/thaw cycling massively influence oxylipin patterns (60). Interestingly, Giera and coworkers also show that the oxylipin pattern in EDTA plasma is not stable when stored at $-80^{\circ} \mathrm{C}$ (57). For most of the oxylipins, small changes were observed over the time span of one year. However, two critical oxylipins, i.e. $\mathrm{TxB}_{2}$ and 12-HETE, were found to increase (2-20 fold and 1.5-15 fold, respectively) under certain conditions (without methanol or butylated hydroxytoluene (BHT, radical scavenger) addition). As these metabolites are halmark indicators of platelet degranulation $(21,64)$, for long term storage, the preparation of platelet depleated plasma may be advantageous. Taking into account that clinical samples are stored under these conditions, the data for $\mathrm{TxB}_{2}$ and 12-HETE should be evaluated with caution in samples which have been stored over a long period, e.g. samples from prospective cohort studies. In our hands, the oxylipin pattern in human plasma is stable during storage at $-80^{\circ} \mathrm{C}$ for 2.5 years as shown for selected oxylipins in Figure 5. Though this data is only obtained over a period of 2.5 years from a pool of well-prepared EDTA plasma from healthy subjects, it implies that oxylipins can be evaluated in biological samples that have been stored at $-80^{\circ} \mathrm{C}$ for many years. Overall, these 
data demonstrates the importance of carefully controlling all aspects of sample collection and storage to minimize oxylipin variability.

3.3 Sample preparation approach - In general, oxylipins occur in plasma esterified into complex lipids such as phospholipids, triglycerides and cholesterylesters (>90\% of oxylipins (hydroxyPUFA and epoxy-PUFA)), or as free oxylipins, i.e. in their non-esterified form. Esterified oxylipins are commonly quantified in a sum parameter consisting of esterified and free oxylipins (total oxylipins) following hydrolysis by saponification. It should be noted that alkaline conditions destroy the $\beta$ hydroxy-keto PG (e.g. PGEs, PGDs) and Tx, as well as cysteinyl leukotrienes and ketones but not the $\beta$-hydroxy-alcohols (PGFs) (65). Reported conditions for saponification vary using e.g. potassium hydroxide $(0.2-0.5 \mathrm{M}$ in sample $(66,67)$, sodium hydroxide $(0.5-3.75 \mathrm{M}$ in sample $(35,68-70))$ or sodium bicarbonate $(0.1 \mathrm{M}$ in sample (71)). Temperature and duration of hydrolysis range from 4$90^{\circ} \mathrm{C}$ for $20 \mathrm{~min}$ to $18 \mathrm{~h}(35,66-71)$. Moreover, to promote efficient hydrolysis of complex lipids with low solubility including triglycerides and cholesterylesters, transesterification of lipids in methanolic sodium hydroxide in the presence of lipidclass surrogates (i.e. phospholipids, triglycerides, cholesterylesters, and free fatty acids), followed by hydrolysis using water has been established (65). In some protocols an initial liquid-liquid extraction (e.g. chloroform/methanol or cyclohexane/isopropanol/ammonium acetate), or protein precipitation with organic solvents has been used to extract the lipids from the biological sample before hydrolysis $(65,66,68,70,71)$. These different strategies may influence the amount of oxylipins isolated and liberated during hydrolysis and thus directly affect apparent (total) oxylipin concentrations resulting in variations in the reported concentrations. However, only a few reports data on method optimization are presented - as in (67) - and thus so far, the effects of different saponification strategies has not been systematically evaluated.

For analysis of free oxylipins in biological samples, solid phase extraction (SPE) is the most commonly applied technique today, and SPE materials with different retention mechanisms as well 
as different elution solvents are used (72-75) and have been summarized and compared in (76). SPE allows relative enrichement of analytes from larger sample sizes to lower detection limits. Protein precipitation $(57,77)$ and liquid-liquid-extraction $(78,79)$ procedures have also been reported. While counterintuitive, the dilution of samples by protein precipitation procedures can effectively lower detection limits by reducing ion suppression/enhancement influences of co-extracted metabolites. In the SPE protocols, sample pre-treatment strategies have to be optimized for each protocol and include protein precipitation followed by dilution of the samples with buffer - often coupled to $\mathrm{pH}$ adjustment (e.g. using anion-exchange cartridge material) - or acidification of samples. Following elution with appropriate organic solvents, samples are reduced and reconstituted to achieve concentration of analytes of up to 10 -fold (compared to the plasma sample). Differing SPE protocols are most likely one of the most important factors contributing to the high variability in the concentrations of oxylipins in biological samples, such as human plasma of healthy individuals. In a direct comparison of the SPE protocols using the same instrumental setup and the same set of samples (76) it has been shown that apparent recoveries of internal standards added to the samples at the beginning of preparation (i.e. analytical surrogates) varied significantly between protocols. This could be explained by differences in analyte extraction efficiency and/or differential removal of ion suppressing matrix components, such as phospholipids (Figure 6).

Matrix induced ion suppression/enhancement is a key problem when using electrospray ionization-mass spectrometry (ESI-MS) for quantitative analysis in biological matrices (80). Ion suppression can be particularly problematic in targeted oxylipin metabolomics since only a few isotopically labeled internal standards are used for a large number of oxylipins eluting at different retention times. In this context, it has to be kept in mind that matrix differences between individual samples such as different human plasma samples (i.e. healthy vs disease, fasting vs postprandial, normolipidemic vs hyperlipidemic) may also increase variability in results, and assessing the consistency of suppression across samples within any single study should be considered. Moreover, there is an optimum balance between sample extraction and final concentration that can vary by 
sample matrix (e.g. adipose vs liver vs plasma) and may be influenced by the nature of sample extraction and the total lipid levels of the tissues.

Hence, a carefully optimized and well-characterized extraction protocol leading to reproducible analyte concentrations in the analyzed matrix is of the utmost importance for the production of biologically meaningful oxylipin data. If ion suppression is ignored - or not characterized - apparent changes in oxylipin concentration may result from differences in the matrix and not changes in the associated metabolic cascades. Therefore, ideal methods will limit the observable matrix-dependent ionization effects across the entire chromatographic run.

3.4 Analytical hardware - While gas liquid chromatography-MS (GLC-MS) methods were commonly used in the early days of oxylipin quantification, these have been almost completely replaced by (ultra) high performance liquid chromatography-MS ((U)HPLC-MS) methods on reversed phase (RP) columns, which can cover $>170$ analytes from up to six PUFAs precursors including linoleate (C18:2n6), alpha-linolenate (C18:3n3), dihomo-gamma-linolenate (C20:3n6), arachidonate (C20:4n6), eicosapentaenoate (C20:5n3) and docosahexaenoate (C22:6n3) (Table 2). Rare analyses of oxylipins from adrenic acid $(\mathrm{C} 22: 4 n 6)(4,81,82)$ or n3- or n6-docosapentaenoic acid (DPA, C22:5n3/n6) $(4,83)$, and very long chain elovanoids (84) have also been reported. Recent articles describe the use of super-critcial-fluid chromatography (85). Because oxylipins in their non-esterified form bear the acidic carboxy-moiety of the polyunsaturated fatty acid precursor, ionization is dominantly carried out by ESI in negative ion mode. Only in a few applications different techniques are used, e.g. atmospheric pressure chemical ionization following derivatization (86) (Table 2).

Today, oxylipins are most often quantified using triple quadrupole MS (QqQ-MS) (Table 2). This type of analyzer is well suited for the detection of oxylipins because of its high ion transmission and matrix independence (compared to Paul traps or linear ion traps). In addition, these systems are generally coupled with either photomultipliers or electron multipliers, providing linear detector responses over concentration ranges of 5-6 orders of magnitude. The latter is crucial for oxylipin 
quantification because levels of analytes differ in the very same sample by well over three orders of magnitude, e.g. in plasma of healthy humans from 0.050 to $11 \mathrm{nM}$ (11,12-DiHETE and 15,16-DiHODE (41)) or in healthy mouse plasma (following feeding with omega-3 fatty acids) from 0.064 to $495 \mathrm{nM}$ for PGE $\mathrm{P}_{2}$ and 12-HEPE (56) (data obtained from the mean reported concentraton within one group). Pathophysiological conditions induce strong changes where a linear range of at least four orders of magnitude is needed $(45,55)$. A key feature of QqQ-MS is that oxylipins are detected following fragmentation. Given that oxylipins are formed by oxygenation of unsaturated bounds within the PUFA backbone, their (exact) molecular masses cannot distinguish regioisomeric structures. Thus, only fragmentation makes a specific MS-detection of isobaric compounds possible. It is important to remember, however, that oxylipin regioisomers can often generate non-specific fragments, and care must be taken in both quantitative ion selection and chromatographic resolution of certain spieces (87). However, QqQ-MS only allows the analysis of pre-selected species, i.e. "targeted metabolomics", and today analyses of 50-200 oxylipins are common (Table 2). Using time of flight (TOF) or orbitrap mass analyzers equipped with a quadrupole collision cell (e.g. qTOF or Q Exactive ${ }^{\mathrm{TM}}$ ) allow acquisition of full (fragment) spectra making simultaneous targeted and non-targeted oxylipin metabolomics/lipidomics possible. To date, few applications with these instruments have been published, most being qualitative $(88,89)$. At present, using two methods for non-targeted (orbitrap) and targeted (QqQ) metabolomics, as recently described by Wheelock and coworkers (42), is the most promising approach for gaining both, lipidomics data and quantitative information on oxylipins.

3.5. Isomeric and enantiomeric complexity - Due to the complexity of oxylipin isomer profiles present in biological samples, careful selection of collision induced mass transitions along with high chromatographic resolution and stable retention times are required to yield the selectivity and sensitivity needed to correctly identify and quantify oxylipins. Thus, effort is required for optimizing both the mass spectrometric parameters and the chromatographic method, to avoid peak misalignment and/or mass spectrometric overlap of secondary ions which can lead to the generation 
of inaccurate data leading to false conclusions. The importance of selective mass transitions is illustrated by Figure 7. Two transitions of the hydroxylated-DHA 17-HDHA were used to quantify the analyte in human plasma and rat liver. In both matrices, the selective transition yields clean chromatograms with only one peak while using the unspecific transition results in several peaks. These interfering peaks hamper peak integration and thus might lead to variations in apparent concentrations.

In addition to selective MS detection, the large number of isomeric oxylipins require excellent chromatographic separation. Currently, separation is typically carried out by reversed phase chromatography often using columns filled with sub-2- $\mu \mathrm{m}$ or fused core particles (Table 2).

The fragment spectra of several oxylipins, particularly regio- and stereoisomers are often too similar to be resolved spectrally. An example of such a critical separation pair, i.e. two oxylipins with the same precursor mass giving rise to similar fragment spectra, are the hydroxylated-AA metabolites 9HETE and 12-HETE (90). Similarly the most sensitive transition for 8(9)EpETrE also shows signals for 11(12)EpETrE (87) making these two epoxy-AAs another critical pair requiring chromatographic baseline separation. Even using optimized MS-transitions and optimal (state of the art) reversedphase liquid chromatography, isobaric interferences from the sample matrix could overlap with the oxylipin peak. This is particularly a challenge in the detection of multiple-hydroxylated PUFA such as specialized pro-resolving mediators (SPM), with a large number of possible regio- and stereoisomers. Well characterized examples for this, which - if not recognized - lead to strong variations in the apparent concentration (i.e. poor accuracy), are the interference between $\mathrm{LTB}_{4}$ and $5(S), 12(S)$ diHETE (91) and different isobaric compounds mimicking lipoxin A4 $\left(\mathrm{LXA}_{4}\right)$ (79). Similarly, interfering peaks for Maresin 1 (MaR1), and the protectins PD1 and PDX occur in improperly stored plasma (57). Complicating matters, trans-double bond containing oxylipins also exist, produced by either the metabolism of trans-fatty acids or the rearrangement of formed oxylipins (92-94). 
Another significant consideration in oxylipin analyses is the chirality of the detected species.

382

383

384

385

386

387

388

389

390

391

392

393

394

395

396

397

398

399

400

401

402

403

404

405

406

In particular, independent detection and quantification of enantiomers can aid in interpretation of results in a biologically relevant context. For instance, a variety of oxylipins can be produced by the direct interaction of reactive oxygen species with unsaturated lipids, with the resulting products having no enantiomeric enrichment, while enzymatic reactions generally have high degrees of enantiomeric enrichment (95-102). Notably, the clotting process yields dramatic shifts in oxylipin enantiomeric patterns (99). In addition, some enzymes yield the opposite enantiomers of the same regioisomers, for example 12(R)-HETE production by CYPs and psoriatic lipoxygenases, and $12(S)$ HETE production by the ALOX12 gene product $(103,104)$. Historically, these techniques have relied upon normal phase chromatography of pentaflurobenzyl ester derivatives, however new reverse phase chiral materials are opening the door to routine application of these methods in the future. (100-102). Recently developed approaches couple a non-chiral reversed phase-column with a chiral amylose-based column that can be used with reversed phase solvents $(101,105)$. These were used e.g. to successfully unveil the stereospecific formation/degradation of epoxy-PUFA and hydroy-PUFA (101) as well as the characterizing the configuration of SPMs (105).

3.6. Accessibility of analytical calibrants and internal standards - To accurately quantify oxylipins, a calibration with authentic reference compounds is required, typically carried out by external calibration with internal standards introduced to the samples, thus allowing correction for methodological variance (e.g. sample loss, ion suppression). Currently, several hundred nonesterified oxylipins are commercially available through a small handful of companies. However, oxylipins esterified into complex lipids including triacylglycerides, phospholipids, cholesterylesters and appropriate isotopically labeled analogs are essentially unavailable through the commercial market place and thus only available to those scientists with the skill and resources to synthesize and purify them. With respect to the available standards, varying purities of these reference compounds have been reported (106), which is likely one cause of the massive differences in reported concentrations $(52,107)$. The limited availability of isotopically labeled structural analogs, and their 
non-uniform application in these analyses likely exacerbates this problem. Recently, verifiedconcentration standards, i.e. quantitative grade standards, became available for selected compounds, such as MaxSpec ${ }^{\mathrm{TM}}$ (Cayman Chemicals, Ann Abor, MI, USA) and are supplied with batch-specific certificates of analysis. However, up to now only a few standards are available and we recently suggested a strategy to quantify non-verified material with these few verified-concentration standards (106).

Despite optimizing and standardizing sample collection, preparation and analysis, inter- and intra-day variation will remain. Recent studies show that an intra-day variation of $<20 \%$ can be achieved for most analytes in human plasma when present at concentrations above the lower limit of quantification (LLOQ) (41). However, variability increases as analyte concentrations approache the LLOQ. Therefore, methodological robustness should be considered when interpreting results, particularly when the null hypothesis is not rejected. Such robustness factors should include method variability along with other validation criteria such as internal standard recoveries, detected matrix effects, sensitivity (i.e. LLOQs), and calibration stability and accuracy. To this end, we would encourage the routine reporting of these robustness factors, which are rarely reported outside of method development studies at this time.

When comparing oxylipin concentrations from different laboratories (Table 2), it is important to consider the analytical choices within each method. Round-robin trials comparing methods established and routinely implemented in different laboratories will be the key to identifying strengths, weaknesses, and intercomparability of different approaches. Ultimately, such efforts will allow the implementation of internationally agreed upon sample preparation procedures and/or a routine performance standard that will allow the highest confidence in these important data sets, and promote the direct comparison of studies performed at multiple locations. Ongoing effort in different national projects e.g. German Research Foundation 41696725 (http://gepris.dfg.de/gepris/projekt/4169672511) or international projects such as the EU JPI-HDHL 
OXYGENATE project (https://www6.inra.fr/ipi-hdhl-biomarkers-oxygenate/) aim to address these questions. However, until these procedures have been established a comparison of the (absolute) reported concentration of oxylipins should be performed carefully, and only the relative change within the studies seems to be a measure which can be robustly compared.

Accurate analyte quantification requires signal to noise ratios to exceed a defined threshold.

This is comprehensively discussed in internationally accepted guidelines on method validation (European Medicines Agency, US food and Drug Administration, US Environmental Protection Agency, etc.). With a signal/noise ratio of at least 5, the typically reported LLOQ for oxylipins on state-of-the-art QqQ instruments is $\sim 0.5$ to $50 \mathrm{fmol}$ on column (Table 2). The LLOQ varies about 10-fold between different oxylipins based on their ionization and fragmentation behavior. Proper definition of analyte specific LLOQs in the methods used is crucial, because it impacts the breadth and number of oxylipins that can be reported in a biological sample. Reporting levels below the LLOQ need to be identified as they are prone to high variation and inacceptable accuracy. It should be stressed, however, that while measures below the limit of detection (LOD) are not an indication of the presence or absence of a compound, and those below the LLOQ (above the LOD) are subject to higher false positive/false negative rates (108), they may have statistical value in maintaining the number of observations across all analytes, and may be better than removal and imputation or arbitrary replacement by the LLOQ, procedures that should be implemented with great care (109111). Taking an injection volume of 5 to $10 \mu \mathrm{L}$ and an average molecular mass of 300 Da into account, as a rule of the thumb the LLOQ for oxylipins in the injected solution is between 0.1 and 10 $\mathrm{nmol} / \mathrm{L}(0.3$ to30 $\mathrm{ng} / \mathrm{mL}$ ). The detection of lower concentration of oxylipins becomes possible by preconcentration during sample preparation if a concurent increase in ion suppression is not observed.

\section{Inter-individual variability of plasma oxylipin patterns.}

As illustrated in Figure 3, plasma concentrations of oxylipins are highly variable in clinically healthy humans and each oxylipin has its own variability. Both, environmental and intrinsic factors can 
contribute to variance in measured oxylipin patterns, which are independent of analytical variability.

Such natural variance of systemic oxylipins can stem from changes in either substrate availability or modulating the expression and/or activity of responsible biosynthetic enzymes.

\subsection{Influence of environmental factors on oxylipin patterns - Oxylipin patterns reflect the} integration of many factors, most notably the availability of unsaturated fatty acid precursors, the relative abundance and activity of specific enzymes, and the degree of oxidative stress present in the individual at the time of sample collection. Each of these factors is influenced by the environment.

Diet constitutes the single largest environmental factor that modulates both the type and dose of PUFAs available for oxylipin biosynthesis. Oxylipins can be produced either directly in phospholipid membranes (e.g. non-enzymatically or via 15 -LOX pathways) $(112,113)$, however for most enzymes, the esterified PUFAs have to be released from membranes by the action of phospholipase A2 (PLA2) (114). In most human tissues and circulating cells, the omega-6 PUFAs (i.e. arachidonic acid and linoleic acid) are the most abundant PUFAs stored in membranes $(115,116)$ and therefore the main substrates for oxylipin biosynthesis. However, changing dietary PUFAs (type and dose) can readily modify the fatty acid composition of cellular lipids. This has been well demonstrated with increased intake of long chain omega-3 PUFAs (i.e. EPA and DHA) from fish or fish oil based supplements, which leads to dose- and time-dependent incorporation of both fatty acids in blood lipids, blood cell lipids, and many tissue pools $(49,117,118)$ (and see review (119) for more details). The incorportion of long chain omega-3 PUFAs is usually accompanied by a decrease in omega-6 PUFAs including linoleic, dihomo- $\gamma$-linolenic and arachidonic acids (119), but the rate and magnitude of these changes are dependent on an individuals basal omega-3 status (49). Changing the relative proportion of omega-3 and omega-6 PUFAs in membranes influences oxylipin patterns because of both shifts in substrate availabilityand variable substrate affinity with the different enzymes. For instance, cytosolic PLA2 has a strong affinity for AA and EPA but very weak interaction with DHA, which is preferentially hydrolyzed by the calcium-independent PLA2 (iPLA2, Type VIA) (120). A difference in substrate 
affinity was also reported for COX-2, which preferentially oxidizes AA while having a much weaker interaction with EPA, and almost no affinity for DHA (121). Concerning the CYP pathway, the affinitiy of CYP isoforms with PUFAs depends on the carbon chain length as well as the type and number of unsaturations. Interestingly, double bonds in the omega-3 position offer a preferential epoxidation site for many CYPs including CYP1A, CYP2C, CYP2J and CYP2E, while CYP4A also predominantly hydroxylates the terminal methyl-group of EPA and DHA (see (122) for more details). Consistently, Fisher et al. demonstrated that CYP dependent-epoxide formation from EPA and DHA were 8.6-fold and 2.2-fold more efficient than AA, respectively (123). Basically, in healthy subjects, long chain omega-3 PUFA supplementation can elevate total EPA and DHA oxylipins at the expense of total AA oxylipins $(45,49,52)$. Similar, but less consistant results have been reported for free oxylipins (52). Relative changes in EPA are generally more pronounced. Crossvalidating the effects of omega-3 PUFA supplementation on the different pathways of biosynthesis between different studies produces no systematic trends (52). Several authors, however, reported predominant changes in the CYP pathways (123) consistent with a higher affinity of CYP enzymes with omega-3 PUFAs. Recent data demonstrate that the plasma levels of hydroxy-PUFA, epoxy-PUFA and dihydroxy-PUFA derived from n3-PUFA increase in a linear fashion with the intake of n3-PUFA (124).

While PUFA instake can alter substrate availability, other factors can alter oxylipin patterns through modification of the expression and/or activity of enzymes of the oxylipin pathways. The first environmental factor to consider when interpreting oxylipin profiles should be the use of drugs that specifically target oxylipin pathways. These notably include non-steroidal anti-inflammatory drugs (NSAIDs), which act via the inhibition of COX isoenzymes and are one of the most widely used drugs in global pharmacological management of acute and chronic pain (125). Other examples are 5-LOX inhibitors (e.g. Zileuton) in the treatment of allergy and asthma, or antithrombotic agents (e.g. Dazoxiben, Camonagrel, Picotamide) that inhibit Tx synthases. Of note, even for these widely used and well characterized drugs, responses are complex and impacts on oxylipin patterns are often broader than expected (51). For instance, the use of celecoxib, a specific COX-2 inhibitor, in patients 
with colon polyp, was associated with increased levels of CYP- and LOX-derived oxylipins (126), which could be a result of substrate shunting into these alternative pathways. Other drugs not specifically designed to modulate enzymes of the oxylipin pathways can also influence oxylipin patterns. This is notably the case of statins, inhibitors of HMG-CoA reductase, which are widely used in the treatment of hypercholesterolemia. Statins have been shown to increase the production of COX-2-derived oxylipins in various tissues via S-nitrosylation of COX-2 (127-130), while only modest changes in 5LOX metabolites appeared in the non-esterified plasma pool with high-dose simvastatin (131). Phytochemicals in medicinal herbs or plant-based foods (i.e. alkaloids, polyphenols, terpenoids and plant-derived lipids) also influence the activity of oxylipin enzymes. Among them, polyphenols are representative and nutritionally significant coumpounds investigated for the last 30 years. Numerous in vitro cell-based or enzyme-based assays support the inhibitory effects of various dietary polyphenols including flavonoids, curcumin, stilbenes and secoiridoids on PLA2, COX and 5-LOX and CYP gene expression and/or activity (132-137). Of note, some of this in vitro evidence should be interpreted with caution since they often arise from experiments conducted using native compounds rather than circulating forms of polyphenols and at high doses not achievable through diet. However, short term or long term controlled dietary interventions have reported significant modulation of systemic COX- and LOX-derived oxylipin levels following intake of polyphenol-rich foods in healthy humans $(138,139)$ even though interindividual variability sometimes hamper such demonstration (140). Other general life style habits such as smoking $(141,142)$, alcohol consumption (143) or physical activity $(144,145)$ can also influence systemic oxylipin patterns through an increased inflammatory state caused by the combined effects of inhaled mediators and/or oxidative stress.

4.2 Influence of intrinsic factors on oxylipin patterns - Intrinsic factors that can modulate oxylipin profiles include such variables as age, sex, and genetic polymorphisms, all of which have the potential to modulate biosynthetic enzyme expression and/or activity. Various disease states such as infections or cardiometabolic disturbances (e.g. obesity, type 2 diabetes) also influence oxylipin biosynthesis but this will not be discussed here. 
While not comprehensively investigated, several independent studies in both animal models

535

536

537

538

539

540

541

542

543

544

545

546

547

548

549

550

551

552

553

554

555

556

557

558

559

and humans have reported a significant influence of age and sex on oxylipin levels $($ see $(146,147)$ for

recent compilation of the literature). Aging is generally associated with increased levels of COXderived oxylipins including $\mathrm{PGE}_{2}$, 6-keto- $\mathrm{PGF}_{1} \mathrm{a}, \mathrm{TxB}_{2}$ and their stable metabolites 2,3-dinor $\mathrm{TxB}_{2}$ and 2,3-dinor-6-keto-PGF ${ }_{1} \alpha$. Levels of pro-inflammatory leukotrienes (e.g. $\mathrm{LTB}_{4}, \mathrm{LTC}_{4}$ ) and hydroxy fatty acids (e.g. 5-HETE) derived from the LOX-pathway are also higher in biological fluids or tissues from aged individuals compared to younger ones. On the contrary, pro-resolving LOX-derived oxylipins (e.g. $\mathrm{LXA}_{4}, \mathrm{LXB}_{4}, \mathrm{Mar1}, \mathrm{RvD1}$ ) are generally found in lower abundance in aged individuals with the exception of PD1, which was reported to be increased in the brain of aged mice (146). Other oxylipins produced by sequential LOX and CYP enzymes or autoxidation of linoleic acid $(98,148)$, namely 9,10,13- and 9,12,13-TriHOME, were also higher in plasma of old healthy men and women in comparison with younger controls (146). The effects of aging on CYP-derived oxylipins in humans are more scarce and contradictory (149). Most studies have investigated the expression or activity of CYPs at the hepatic level, but the difficulty in accessing human liver samples hampered the demonstration of a significant effect of aging on human CYPs and its consequences on the production of CYP-derived oxylipins. According to the free radical theory of aging (150) and knowing the role of reactive oxygen species (151) and lipid peroxides (3) in the regulation of the expression/activity of COX and LOX, oxidative stress is likely a contributing factor to the effect of aging on oxylipin patterns.

Modulation of oxylipin biosynthesis by sex was reported more than 50 years ago (152). Sexual dimorphism of oxylipin pathways depends on the type of tissue investigated as well as the hormonal status of individuals, which is itself age related. However, males generally have higher levels of $\mathrm{PGE}_{2}$ and $\mathrm{Tx}$ derived from the COX pathway, while females have higher levels of leukotrienes but lower levels of pro-resolving oxylipins, both produced by LOX enzymes (See detail in (147). This is consistent with the higher preponderance of leukotriene-related diseases such as asthma and rheumatoid arthritis in women. Sex is a known factor influencing CYP-dependent drug metabolism (153), but conflicting results were reported in relation to oxylipin metabolism and it is difficult to 
ascertain if gender has a significant influence on the expression/activity of oxylipin generating CYPs (149). However, there are clear sex differences in the levels and distribution of the soluble epoxide hydrolase (sEH), an important epoxy fatty acid converting enzyme (154). It should be noted that, when looking at comprehensive oxylipin profiles, which has been rarely done so far, the overall effect of sex and its interaction with other factors makes interpretation more complicated. Recent studies in rats showed that $\sim 40 \%$ of oxylipins (from profiles including $60-71$ oxylipins) were influenced by sex and almost all were higher in male rats $(155,156)$. These studies also showed that sex differences are influenced by diet (e.g. male rats have higher levels of adipose oxylipins when fed a high DHA diet, while females have higher oxylipins when fed a high EPA diet), by the type of precursor PUFA (e.g. rat kidney DHA derived oxylipins are higher in females, while AA derived oxylipins are more often higher in male) and by tissue (e.g. in kidney, DHA oxylipins are influenced by diet and sex whereas no change is observed in liver). Mechanisms underlying the influence of sex on enzymes of the oxylipin biosynthetic pathways logically include a regulation of expression/activity by sex hormones. Their role as modulators of COX pathways remains unclear, with investigations mainly focused on primary enzymes of the pathway (i.e. COX). On the other hand, differences in LOX-derived oxylipins have been directly related to variant androgen levels in men and women (147). This can be the result of a direct modulation of LOX enzymes by sex hormones but other regulatory aspects of the LOXdependent oxylipin formation including interaction with other proteins (e.g. 5-lipoxygenaseactivating protein or FLAP), subcellular localization, phosphorylation and other factors (e.g. ATP, glyceride, redox tone, $\mathrm{Ca}^{2+}$ ) (3) may also be affected by sex and sex hormones.

Genes of enzymes involved in the biosynthesis of oxylipins are highly polymorphic, which may contribute to the variability of oxylipin patterns in healthy humans. However, human genetic studies mostly focused on clinical outcomes rather than oxylipin metabolism. Several large studies investigated the associations between the polymorphism of primary oxylipin enzymes (i.e. COX, LOX and CYP) and the risk of diseases involving oxylipins, such as CVD and cancer. For instance, Ross et al. conducted a remarkable study to prospectively explore the association of a COX-2 variant (i.e. 

rs20417) in 49,232 participants. The results showed that rs20417 variant was associated with a reduced risk of major cardiovascular events (157). Common polymorphisms in the 5-LOX pathway including variants of 5-LOX, FLAP, LTA ${ }_{4} \mathrm{H}$ and $\mathrm{LTC}_{4} \mathrm{~S}$ were associated with myocardial infarction in a recent case-cohort study conducted in 3000 participants of the Danish Diet, Cancer and Health study (158), and promoter region variants in the ALOX5 have been linked to the efficacy of fish oil modulation on cardiovascular risk (159). Genetic variability of 5-, 12- and 15-LOX enzymes and FLAP may also affect colorectal neoplasia as reported in three US population-based case-control studies of colorectal cancer involving 5,625 subjects (160). CYP metabolites (i.e. EpETrE) having recognized cardioprotective effects (161), associations between CYP and SEH polymorphisms and CVD have been intensively investigated. Even though some studies detected significant associations between several variants of CYP and CVD, contradictory results, probably due to ethnic variability, environmental factors (e.g. smoking) and gender specific effects, have been reported and hamper conclusions of significant associations $(162,163)$. Associations between sEH polymorphisms and CVD have been investigated in case-cohort samples of the Atherosclerosis Risk in Communities (ARIC) study. In a first sample of 1,336 participants, two common haplotypes with opposing effects showed significant associations with the risk of ischemic stroke in African American subjects (164). In a second study involving 2,065 participants of the ARIC cohort, Caucasians with the K55R polymorphic variant allele of $S E H$ were found to have a higher risk of $C A D$ and an increase in the relative abundance of linoleate-derived diols relative to their epoxide precursors (165). Similarly, the most common epoxygenase gene polymorphism has been associated with a significant decrease of enzymatic activity and consequently EpETrE biosynthesis (162). Other evidence of a polymorphism-dependent effect on oxylipin levels were reported by Ross et al. (157) in which COX-2/rs20417 carriers had significantly lower urinary levels of Tx and prostacyclin compared to non-carriers. Concerning the LOX pathway, common variants generally have no functional consequences and loss-of-function variation of the human LOX genes are rare (global allele frequency $<0.1 \%)(166)$. Nevertheless, an intervention study conducted in 116 healthy adults reported that 5-LOX gene variants were associated with 
altered production of AA, EPA and DHA derived LOX-metabolites (i.e. hydroxy and oxo-fatty acids but not leukotrienes) and different response to omega-3 (i.e. fish oil) supplementation (159).

While poorly studied and being more a concern of intra-individual variability, temporal changes in both plasma and urinary oxylipins have been reported. Temporal changes in plasma oxylipins may be linked to meal induced changes (41), however, circadian rythms in arachidonic acid metabolism have also been reported (167) and circadian effects on other aspects of lipid metabolism are well documented (168). Similarly, urinary CYP-dependent metabolites were found to oscilate independent of meals in free feeding men and women (87). As oxylipins are also important regulators of renal water retention and as urinary but not plasma levels are dramatically influenced by sodium intake and depuration $(169,170)$, these are also important factors to consider when urinary oxylipin profiling is considered.

\section{Summary and outlook}

Oxylipins represent an important regulatory cascade and continuing to unravel this system and its intricate interactions has the potential to offer great value to society. To maximize the utility of this information and accelerate our gain in knowledge, it will be critical (i) to promote our ability to directly compare results generated by independent research teams and (ii) to be able to distinguish abberant oxylipins pattern from natural variance. To do this, sources of variance, both analytical and biological, must be identified, minimized where possible, and considered during data analysis and interpretation.

The preanalytical sources of variance are large and best practices along with international standardization in sample collection, storage and preparation should be established. Based on our own understanding of the current literature, we would argue for the use of EDTA plasma and to centrifuge and store samples at $-80^{\circ} \mathrm{C}$ immediately after collection. A first important point to consider for sample preparation is the choice of analyzing total (i.e. free and esterified) or only free oxylipins, as this choice will have important consequences on the oxylipin profiles and subsequent 
biological interpretation. Of note, total oxylipins represent the major portion of circulating oxylipins and may be less affected by sample collection, processing or storage, but their quantitative anaysis currently requires hydrolysis, which destroys several COX-derived oxylipins. Subaliquots of $100 \mu \mathrm{L}$ of plasma for total (free and esterified) oxylipin analysis or of $500 \mu \mathrm{L}$ for free oxylipin analysis should be stored at $-80^{\circ} \mathrm{C}$ in methanol pre-cleaned polyethylene tubes until use. This procedure should reduce artifacts associated with freeze/thaw cycling and platelet activation after prolonged storage.

Differences in sample preparation procedures (i.e. SPE, liquid-liquid extraction, protein precipitation), the application of analytical internal standard corrections (i.e. which isotope labeled internal standard is being used to correct for which specific analytes) and the purity of calibration standards are likely sources of variance in comparing results from different laboratories. In particular, matrix effects resulting in ion suppression of analytical internal standards that do not coelute with their analytical target may lead to inaccurate, while reproducible results (systemic error). Therefore, researchers should take care in assessing the stability of their internal standard recoveries across all samples within their study. First, they should be sure that ion suppression does not segregate by experimental group and they should report all internal standard recoveries as metadata to the study so that others can assess to what degree corrections for loss/suppression are being applied to the reported data, as this may influence the accuracy and thus global comparability of the results.

In terms of analytical variability, in general, modern analytical hardware if well maintained is exceptionally stable. Much more important are the standards used to calibrate these instruments, and control over factors including ion suppression/enhancement. The greatest need in the scientific community are the availability of analytical standards and an increased suite of isotopically labeled analogs, including those which allow the direct quantitative analysis of oxylipins within complex lipids. It would be valuable for the research community to establish priorities for the production of new analytical resources for this field. Moreover, the concentration of all standards used should be 
662

663

664

665

666

667

668

669

670

671

672

673

674

675

676

677

678

679

680

681

682

683

684

685

686

687

validated based on concentration-verified standard material. Until certified standards are available for all oxylipins quality assessment strategies as described by Hartung et al. (106) have to be implemented in each analytical lab.

Beyond these procedural and analytical factors, environmental and intrinsic factors tremendously contribute to the natural variability of oxylipin profiles. Care should be taken during the analysis of human studies to truely test assumptions of population normality prior to committing to simple mean testing as a primary outcome. While the accumulating literature shows that dietary and pharmacological components together with age, sex and genetics all have the potential to modulate substrate PUFAs and/or enzyme activities to shift oxylipin profiles, the natural variance of each circulating oxylipin has not been established so far. This will be crucial to appropriately power experimental designs and to enhance the identification of reliable and relevant biomarkers of disease. Increasing our knowledge regarding the natural variance of oxylipin biosynthesis is also of great interest in personalized nutrition or medicine. These efforts will provide new understanding regarding the variability of individual' responses to dietary factors and therapeutics, thus offering insights into diseases susceptibilitythat may allow for patient stratification and personnalization of disease management. Similarly, if unique response phenotypes are observed within an experimental population, it may be important to develop new hypotheses surrounding the associations of oxylipins and health risks to truely understand the utility of these potential biomarkers in clinical research.

Therefore, moving forward, if we conciously control analytical variance while embracing biological variance as a research community, we are sure to enhance the impact of our efforts and accelerate our discovery of new knowledge regarding the biological regulation of these important regulatory factors.

\section{Acknowledment}

This work was in part supported by the EU JPI-HDHL OXYGENATE project (https://www6.inra.fr/ipihdhl-biomarkers-oxygenate/). Additional support was provided by USDA Project 2032-51530022-00D and 2032-51530-025-00D. The USDA is an equal opportunity provider and employeer. We 
688 would like to thank Laura Kutzner, Laura Froehlich, Sarah Reuber and Christopher Millan Hidalgo for 689 their help summarizing the data on reported oxylipin methods (Table 2).

690 
Table 1. Selected examples of recent applications of the oxylipin profiling to identify biomarkers from human blood samples.

\begin{tabular}{|c|c|c|c|}
\hline Approach & Method & Main objectives & Reference \\
\hline \multicolumn{4}{|c|}{ Biomarkers of complex disease } \\
\hline $\begin{array}{l}\text { Nested case-control } \\
\text { study }(n=42)\end{array}$ & $\begin{array}{l}\text { EDTA plasma, free } \\
\text { oxylipins }(n=21)\end{array}$ & $\begin{array}{l}\text { - Screen for metabolic perturbations in umbilical cord blood plasma from preterm } \\
\text { infants that did or did not develop subsequent pulmonary hypertension. }\end{array}$ & (59) \\
\hline $\begin{array}{l}\text { Nested } \\
\text { cohort }\end{array}$ & $\begin{array}{l}\text { EDTA plasma, free } \\
\text { oxylipins }(n=12)\end{array}$ & $\begin{array}{l}\text { - Examine the prospective association between plasma fatty acids, oxylipins, and } \\
\text { risk of acute myocardial infarction (Singapore Chinese Health Study). }\end{array}$ & $(43)$ \\
\hline $\begin{array}{l}\text { Nested case-control } \\
\text { cohort study }(n=231)\end{array}$ & $\begin{array}{l}\text { Serum, free oxylipins } \\
(\mathrm{n}=31) \text {, }\end{array}$ & $\begin{array}{l}\text { - Study the metabolomic fingerprint in active rheumatoid arthritis irrespective of } \\
\text { patients' response (BiOCURA cohort). }\end{array}$ & $(171)$ \\
\hline $\begin{array}{l}\text { Nested case-control } \\
\text { cohort study }(n=479)\end{array}$ & $\begin{array}{l}\text { EDTA plasma, free } \\
\text { oxylipins }(n=35)\end{array}$ & $\begin{array}{l}\text { - Determine if oxylipins were associated with ventricular arrhythmias and all cause } \\
\text { of mortality in patients with systolic heart failure (PROSE-ICD prospective } \\
\text { cohort). }\end{array}$ & $(172)$ \\
\hline $\begin{array}{l}\text { Nested case-control } \\
\text { cohort study }(n=667)\end{array}$ & $\begin{array}{l}\text { Serum, Free oxylipins } \\
(\mathrm{n}=46)\end{array}$ & - Investigate the specific signature patterns of oxylipins associated with preclampsia. & $(175)$ \\
\hline Clinical trial $(n=126)$ & Plasma, free oxylipins & - Investigate the association between oxylipin profiles and obesity. & $(176)$ \\
\hline \multicolumn{4}{|c|}{ Biomarker of inflammation and oxidative stress } \\
\hline Clinical trial $(n=14)$ & $\begin{array}{l}\text { EDTA plasma, free } \\
\text { oxylipins }(n=51)\end{array}$ & $\begin{array}{l}\text { - Investigate the alterations of oxylipin profiles in response to biodiesel exhaust } \\
\text { exposure. }\end{array}$ & (177) \\
\hline $\begin{array}{l}\text { Nested case-control } \\
\text { study }(n=42)\end{array}$ & $\begin{array}{l}\text { EDTA plasma, total } \\
\text { oxylipins }(n=75)\end{array}$ & $\begin{array}{l}\text { - Characterization of inflammation and oxidative stress during the early phases of } \\
\text { sarcopenia (PROOF cohort). }\end{array}$ & $(47)$ \\
\hline
\end{tabular}




$\begin{array}{ll}\text { Clinical trial }(n=42) & \begin{array}{l}\text { Plasma, free oxylipins } \\ (n=95)\end{array} \\ \text { Clinical trial }(n=1) & \begin{array}{l}\text { EDTA plasma, free } \\ \text { oxylipins }(n=37)\end{array} \\ \text { Clinical trial }(n=10) & \begin{array}{l}\text { EDAT plasma, total } \\ \text { oxylipins }(n=27)\end{array}\end{array}$

- Evaluate levels of inflammatory markers and blood oxylipins in obese subjects before and after weight reduction.

- Investigate postprandial inflammation through changes of oxylipins profiles.

- Characterize oxylipin profile and vascular inflammation following a moderately high-fat meal in Alzheimer's patients.

\section{Biomarkers of nutrition and drug effects}

Dietary intervention $(n=35)$

EDTA plasma, free oxylipins $(n=56)$

Dietary intervention $(n=19)$

EDTA plasma, free oxylipins ( $n=59$ )

EDTA plasma, total oxylipins ( $n=95$ )

Dietary intervention

Dietary intervention $(n=12)$

EDTA plasma, Free oxylipins ( $n=46$ )

Nested case-control Serum, free oxylipins study $(n=231)$

$(n=31)$,

$\mathrm{N}=22$, Heparin HWB,

Ex-vivo experiment free oxylipins ( $n=122)$

Dietary intervention Serum, free oxylipins $(n=40)$ $(n=20)$,

Dietary intervention Plasma, free oxylipins $(n=38)$ $(n=19)$

Dietary intervention Plasma, free oxylipins

$(n=20)$

$(n=38)$
- Determine the impact of long-term treatment with omega-3 fatty acids on plasma oxylipin patterns in patients with severe hyperlipidemia and CVD on standard lipid-lowering and cardioprotective medications.

- Determine the effect of a high-ALA diet on EPA and DHA levels in red blood cells and their oxylipins in the plasma of subjects with a low EPA and DHA status.

- Compare the oxylipin profiles of lipoproteins from healthy vs metabolic syndrome subjects with or without supplementation with omega-3 fatty acids.

- Compare the short and long term effects of DHA supplementation on the oxylipin plasma signature and oxylipin response of stimulated blood cells in healthy men.

- Identify predictors for the outcome of TNFi therapy (BiOCURA cohort).

- Quantitatively map the effects of small-molecule drugs on the entire arachidonic acid cascade.

- Investigate the effects of dietary omega-3 fatty acids on the metabolic signatures of post-menopausal women.

- Evaluate the acute and short-term effects of walnut intake on changes in microvascular function and the relationship of these effects to plasma epoxides.

Determine if oxylipin concentrations change with the consumption of flaxseed enriched foods or differ with subject age. Y 
Table 2. Overview of exemplary instrumental LC-MS-methods covering more than 35 analytes for the quantification of oxylipins. Ionization was carried out by electrospray ionization in negative ion mode on a QqQ instrument and analytes were separated using RP liquid chromatography (C18). Included are sample preparation steps (solid phase extraction (SPE), liquid-liquid extraction (LLE), protein precipitation (ProtPrec)), column dimensions, runtime (including equilibration time), lower limit of quantification (LLOQ) or limit of detection (LOD), internal standards (ISTD) and validation parameter.

\begin{tabular}{|c|c|c|c|c|c|c|c|c|c|}
\hline Lab & $\begin{array}{l}\text { Sample } \\
\text { Preparation }\end{array}$ & $\begin{array}{c}\text { Column } \\
\text { dimensions }\end{array}$ & Runtime $^{1}$ & $\begin{array}{l}\text { LLOQ } \\
\text { range }^{2}\end{array}$ & $\begin{array}{l}\mathrm{Nb} \\
\text { Analytes }\end{array}$ & $\begin{array}{c}\text { Nb } \\
\text { Precursor } \\
\text { PUFA }\end{array}$ & $\begin{array}{l}\mathrm{Nb} \\
\text { ISTD }\end{array}$ & Validation & Ref \\
\hline $\begin{array}{l}\text { Schebb, 2018; } \\
2019\end{array}$ & $\begin{array}{l}\text { ProtPrec, SPM } \\
\text { (plasma, serum, } \\
\text { other body fluids } \\
\text { cell culture) }\end{array}$ & $\begin{array}{l}(150 \times 2.1 \mathrm{~mm} \\
\quad 1.8 \mu \mathrm{m})\end{array}$ & 32 & $0.5-200$ & 175 & 10 & 20 & $\begin{array}{l}\text { calibration curve, LOD, LLOQ, intra- and interday } \\
\text { accuracy and precision, recovery rate, matrix effect }\end{array}$ & $(4,185)$ \\
\hline $\begin{array}{l}\text { Newman, } \\
2014\end{array}$ & $\begin{array}{l}\text { LLE, } \\
\text { saponification, } \\
\text { SPE (plasma) }\end{array}$ & $\begin{array}{l}(150 \times 2.1 \mathrm{~mm} \\
1.7 \mu \mathrm{m})\end{array}$ & 16 & $0.4-14$ & 80 & 6 & 18 & $\begin{array}{l}\text { Calibration curve, precision internal standard } \\
\text { alkaline stability }\end{array}$ & (65) \\
\hline $\begin{array}{l}\text { Newman, } \\
2012\end{array}$ & $\begin{array}{l}\text { LLE, } \\
\text { saponification, } \\
\text { SPE (plasma) }\end{array}$ & $\begin{array}{l}(150 \times 2.1 \mathrm{~mm} \\
\quad 1.7 \mu \mathrm{m})\end{array}$ & 16 & $0.5-100$ & 59 & 6 & 13 & Calibration curve, precision & (49) \\
\hline $\begin{array}{l}\text { Newman, } \\
2002\end{array}$ & $\begin{array}{l}\text { glucuronidase, } \\
\text { LLE (urine) }\end{array}$ & $\begin{array}{l}(150 \times 2.1 \mathrm{~mm} \\
5 \mu \mathrm{m})\end{array}$ & 28 & $60-600$ & 13 & 2 & 2 & $\begin{array}{l}\text { Calibration curve, precision, LOD, LLOQ, standard } \\
\text { additions }\end{array}$ & (87) \\
\hline $\begin{array}{l}\text { Hammock, } \\
2009\end{array}$ & $\begin{array}{l}\text { SPE (serum, } \\
\text { BALF) }\end{array}$ & $\begin{array}{l}(150 \times 2.0 \mathrm{~mm} \\
5 \mu \mathrm{m})\end{array}$ & 21 & $0.1-100$ & 39 & 3 & 8 & $\begin{array}{c}\text { Calibration curve, LLOQ, precision, accuracy, } \\
\text { recovery rate }\end{array}$ & (74). \\
\hline $\begin{array}{l}\text { Holčapek } \\
2019\end{array}$ & $\begin{array}{l}\text { ProtPrec, SPE } \\
\text { (plasma) }\end{array}$ & $\begin{array}{l}(150 \times 2.1 \mathrm{~mm} \\
1.7 \mu \mathrm{m})\end{array}$ & 12 & 7.5-70 & 63 & 6 & 14 & $\begin{array}{c}\text { Calibration curve, LOD, LLOQ, carry-over, precision, } \\
\text { accuracy, recovery rate, matrix effect }\end{array}$ & $(107)$ \\
\hline $\begin{array}{l}\text { Dennis, 2007; } \\
\text { 2010; } 2011\end{array}$ & $\begin{array}{l}\text { SPE (cell culture } \\
\text { media and } \\
\text { plasma) }\end{array}$ & $\begin{array}{l}(250 \times 2.1 \mathrm{~mm} \\
\quad 4 \mu \mathrm{m})\end{array}$ & 20 & LOD: 3-178 & 140 & 7 & 26 & Calibration curve, recovery, LOD & $\begin{array}{l}(186- \\
188)\end{array}$ \\
\hline $\begin{array}{l}\text { Dennis, 2014; } \\
2018\end{array}$ & $\begin{array}{l}\text { SPE } \\
\text { (saponification) } \\
\text { (plasma, cell } \\
\text { homogenates) }\end{array}$ & $\begin{array}{c}(100 \times 2.1 ; 1.7 \\
\mu \mathrm{m})\end{array}$ & 7 & $0.3-810$ & 158 & 9 & 26 & $\begin{array}{c}\text { Calibration curve, LOD, LLOQ, recovery rate, matrix } \\
\text { effect, accuracy, precision, stability }\end{array}$ & $(67,189)$ \\
\hline Dennis, 2011 & $\begin{array}{l}\text { SPE (cell culture } \\
\text { media, rat tissue, } \\
\text { mouse tissue) }\end{array}$ & $(250 \times 2.1 \mathrm{~mm})$ & 25 & $\begin{array}{l}\text { LOD: } 0.3- \\
\quad 3.6\end{array}$ & 141 & 7 & 27 & Calibration curve, LOD & (72) \\
\hline Ceglarek, & ProtPrec, online & $(100 \times 2.1 \mathrm{~mm}$ & 13 & $2.7-156$ & 94 & 5 & 22 & recovery, LOD, LLOQ, calibration curve, precision & $(190)$ \\
\hline
\end{tabular}




\begin{tabular}{|c|c|c|c|c|c|c|c|c|c|}
\hline 2013 & SPE (plasma) & $2.6 \mu \mathrm{m})$ & & & & & & & \\
\hline $\begin{array}{l}\text { Vreeken, } \\
2012\end{array}$ & SPE (plasma) & $\begin{array}{l}(150 \times 2.1 \mathrm{~mm} \\
2.7 \mu \mathrm{m})\end{array}$ & 26 & $1.5-191$ & 104 & 6 & 11 & $\begin{array}{l}\text { Calibration curve, LOD, LLOQ, variation, } \\
\text { reproducibility, matrix effect, recovery, stability }\end{array}$ & (63) \\
\hline Dalli, 2014 & $\begin{array}{l}\text { SPE (plasma, } \\
\text { serum, spleen, } \\
\text { lymph nodes) }\end{array}$ & $\begin{array}{l}(100 \times 4.6 \mathrm{~mm} ; \\
1.8 \mu \mathrm{m})\end{array}$ & $>20$ & $\begin{array}{l}\text { LOD: } 0.05- \\
\quad 0.66\end{array}$ & $>43$ & 3 & 5 & $\begin{array}{l}\text { Calibration, ISTD recovery, matrix interferences, } \\
\text { LOD, stability }\end{array}$ & (191) \\
\hline Dalli, 2018 & $\begin{array}{l}\text { ProtPrec SPE } \\
\text { (body fluids and } \\
\text { tissues) }\end{array}$ & $\begin{array}{l}(100 \times 4.6 \mathrm{~mm} \\
2.7 \mu \mathrm{m})\end{array}$ & $>20$ & & 41 & 3 & 5 & Calibration curve & (192) \\
\hline $\begin{array}{l}\text { Ramsden, } \\
2018\end{array}$ & SPE (plasma) & $\begin{array}{l}(100 \times 4.6 \mathrm{~mm} \\
\quad 1.8 \mu \mathrm{m})\end{array}$ & 35 & $2.7-17$ & 73 & 5 & 9 & $\begin{array}{l}\text { Calibration curve, LOD, LLOQ, precision, accuracy, } \\
\text { reproducibility, matrix effect, recovery, stability }\end{array}$ & (193) \\
\hline $\begin{array}{l}\text { Nording, } \\
2015\end{array}$ & SPE (plasma) & $\begin{array}{l}(150 \times 2.1 \mathrm{~mm} \\
2.5 \mu \mathrm{m})\end{array}$ & $>25$ & $0.0016-11$ & 37 & 4 & 5 & $\begin{array}{c}\text { Calibration curve, LOD, LLOQ, precision and } \\
\text { accuracy, recovery, stability }\end{array}$ & (179) \\
\hline Milla, 2013 & $\begin{array}{l}\text { SPE (whole } \\
\text { blood) }\end{array}$ & $\begin{array}{l}(150 \times 2.1 \mathrm{~mm} \\
1.7 \mu \mathrm{m})\end{array}$ & $>6.5$ & $1.1-1300$ & 122 & 1 & 28 & calibration curve, LLOQ, matrix effect & (194) \\
\hline $\begin{array}{l}\text { Nicolaou, } \\
2013\end{array}$ & SPE (tissue) & $\begin{array}{c}(150 \times 2.0 \mathrm{~mm}, \\
5 \mu \mathrm{m}) \\
(100 \times 2.1 \mathrm{~mm}, \\
2.6 \mu \mathrm{m})\end{array}$ & $\begin{array}{c}30 \\
>30\end{array}$ & $3-600$ & $\begin{array}{l}20 \\
36\end{array}$ & $\begin{array}{l}3 \\
4\end{array}$ & $\begin{array}{l}1 \\
1\end{array}$ & Calibration, LOD & (195) \\
\hline Astarita, 2014 & SPE (plasma) & $\begin{array}{l}(100 \times 2.1 \mathrm{~mm} \\
1.7 \mu \mathrm{m})\end{array}$ & $>14$ & LOD: 0.1 & 112 & 7 & 15 & & (196) \\
\hline $\begin{array}{l}\text { Witkamp, } \\
2012\end{array}$ & $\begin{array}{l}\text { LLE (plasma, } \\
\text { liver, ileum, } \\
\text { adipose tissue) }\end{array}$ & $\begin{array}{l}(100 \times 2.1 \mathrm{~mm} \\
1.7 \mu \mathrm{m})\end{array}$ & 19.75 & & 40 & 4 & 3 & Calibration curve & (197) \\
\hline Zhu, 2015 & $\begin{array}{l}\text { SPE (plasma) LLE } \\
\text { (mouse aorta) }\end{array}$ & $\begin{array}{l}(100 \times 2.1 \mathrm{~mm}, \\
1.7 \mu \mathrm{m})\end{array}$ & 18 & $0.35-12$ & 65 & 3 & 10 & $\begin{array}{l}\text { Calibration curve, LOD, accuracy and precision, } \\
\text { stability }\end{array}$ & (198) \\
\hline $\begin{array}{l}\text { Wheelock, } \\
2018\end{array}$ & SPE (plasma) & $\begin{array}{l}(150 \times 2.1 \mathrm{~mm} \\
2.7 \mu \mathrm{m})\end{array}$ & 21 & & $>46$ & 6 & & Calibration curve & $(42)$ \\
\hline Lee, 2018 & $\begin{array}{l}\text { LLE/ } \\
\text { Saponification / } \\
\text { SPE (plasma, } \\
\text { tissue) }\end{array}$ & $\begin{array}{l}(150 \times 2.1 \mathrm{~mm} \\
2.6 \mu \mathrm{m})\end{array}$ & 20 & & 25 & 4 & 4 & & (199) \\
\hline
\end{tabular}

${ }^{1}$ Runtime in min

${ }^{2}$ LOQ range (low-high) [fmol on col.] 


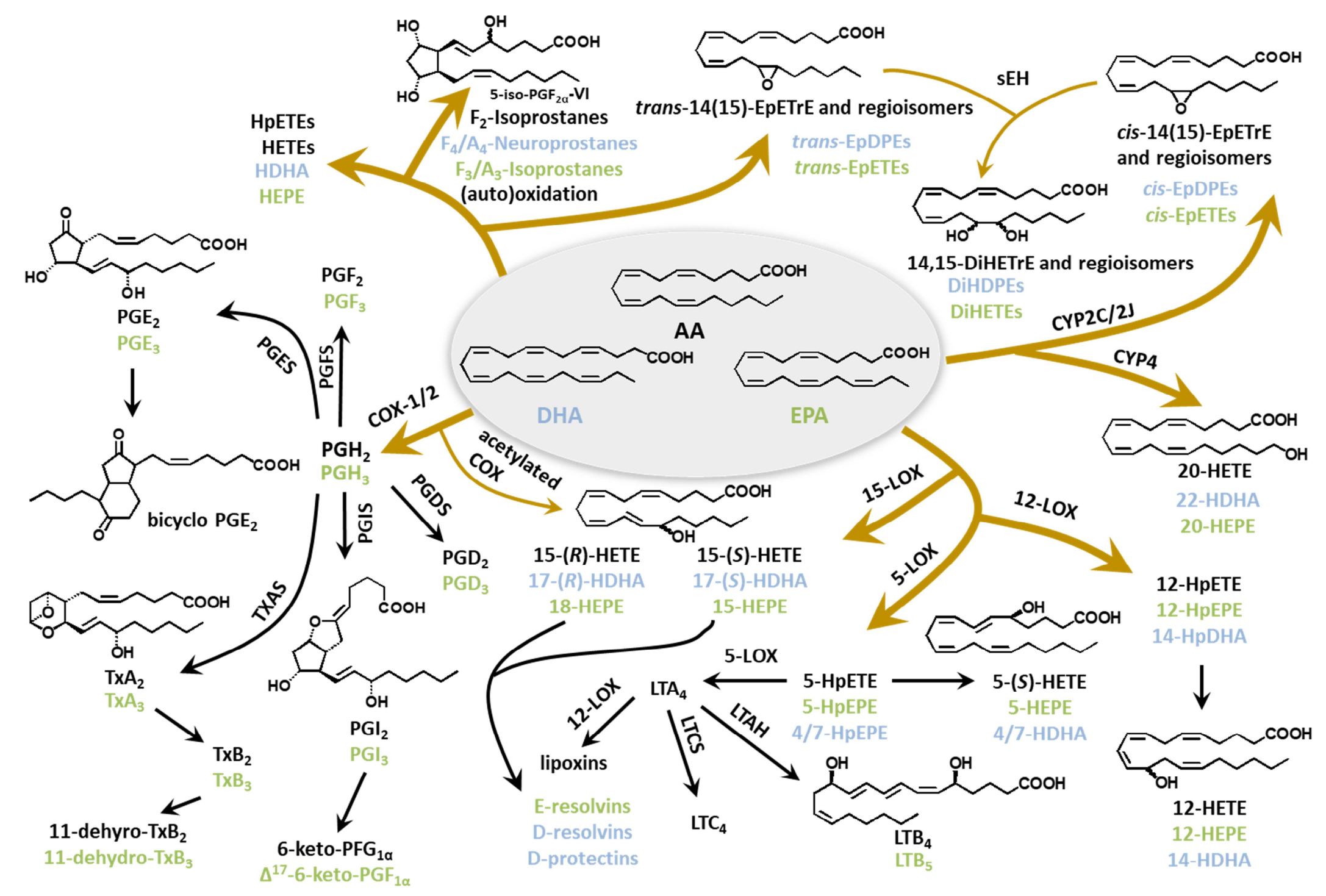

Figure 1. Overview of the main eicosanoids and other oxylipins produced from AA, DHA and EPA through the COX, LOX, CYP and non-enzymatic pathways. 

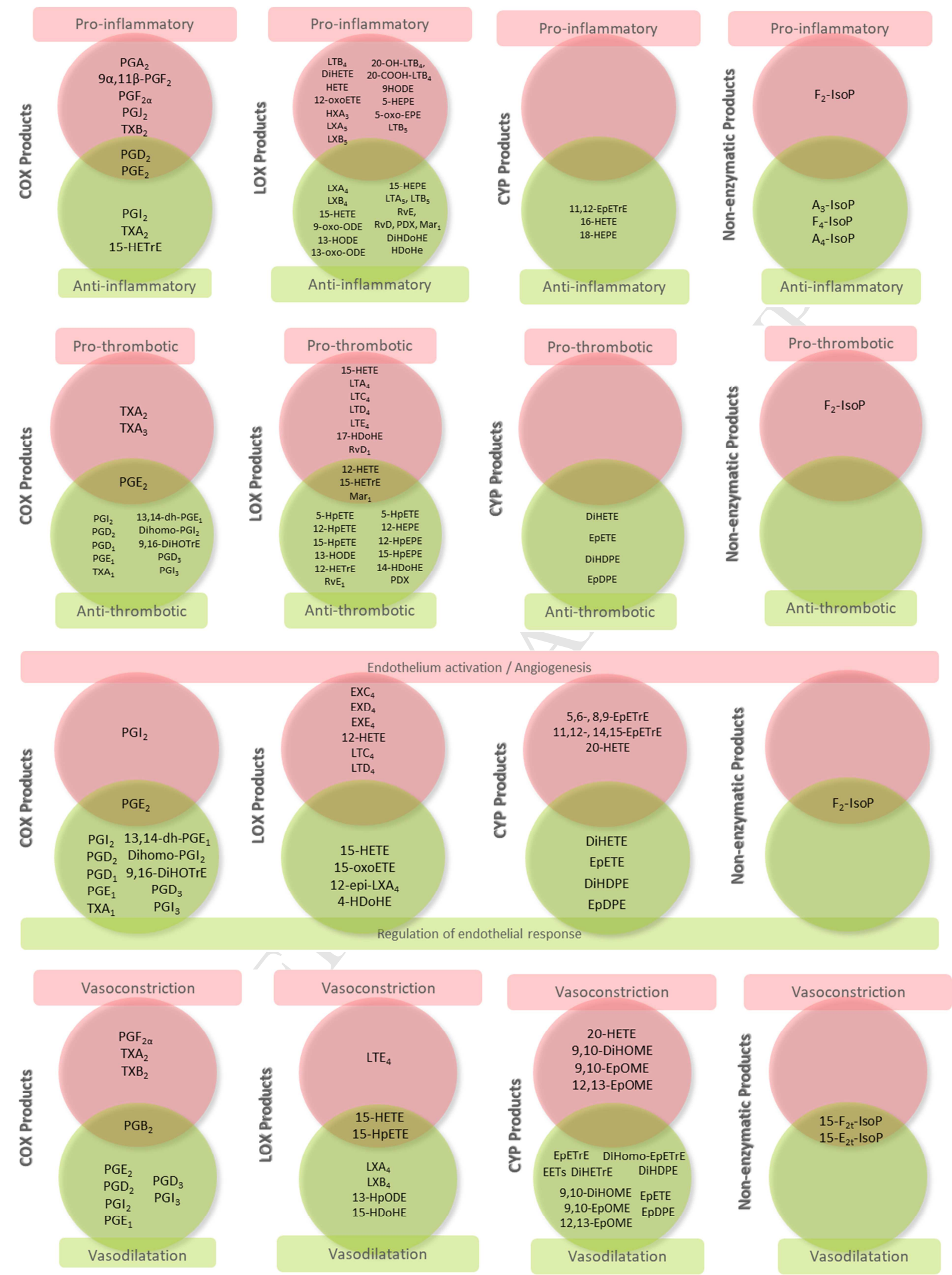

Figure 2. Overview of the complementary and opposite actions of eicosanoids and other oxylipins on inflammation, thrombosis, endothelial function and vascular tone (compilation of data from $(21,200$ 204)). 


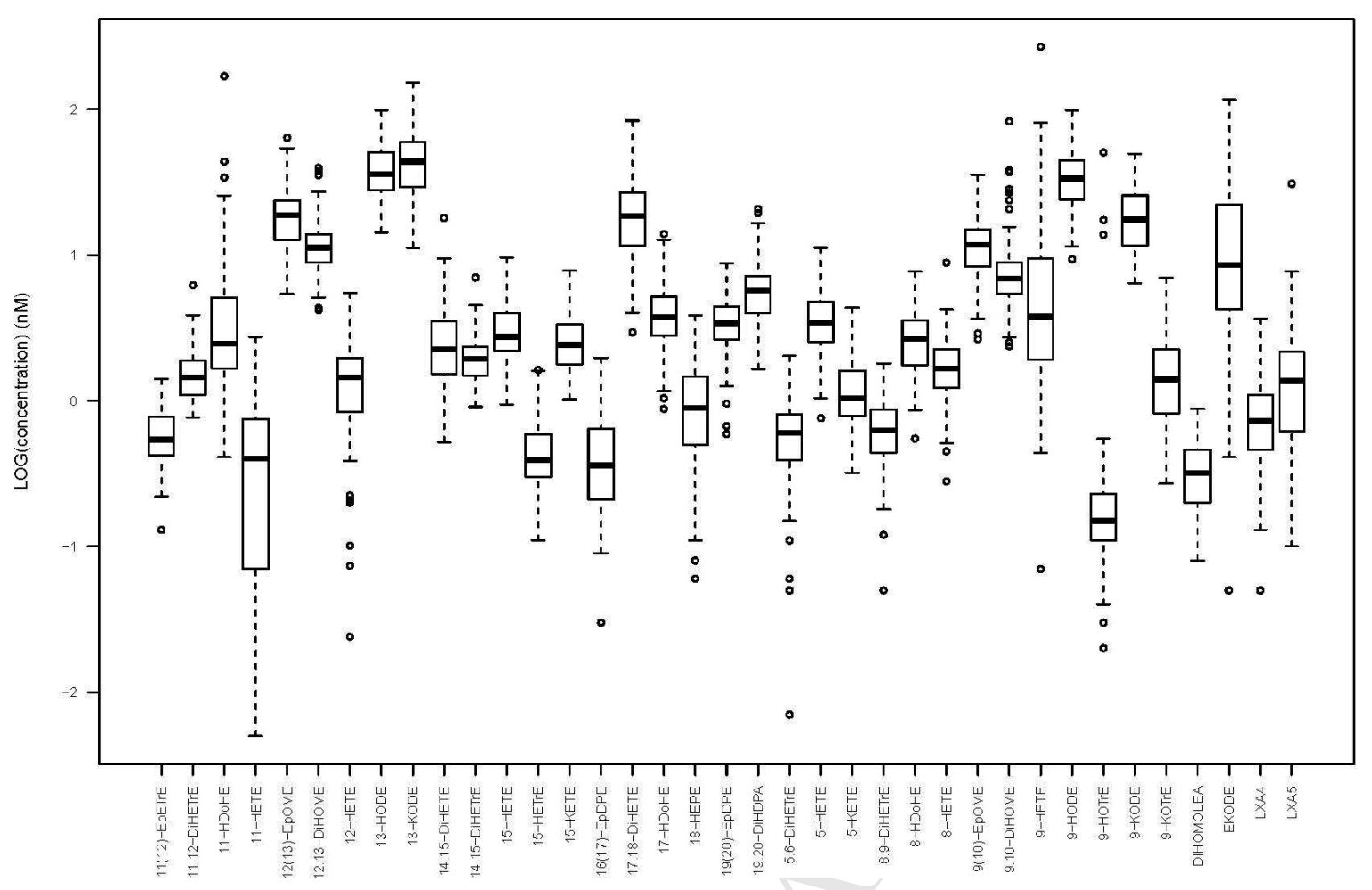

Figure 3. Box-plots from different oxylipins measured in plasma of 133 healthy individuals from the IMPROVE cohort. Mean CV of oxylipin levels for this sample of the IMPROVE cohort was estimated at 87\%. (IIlustration created from supplementary dataset associated with (42)). 


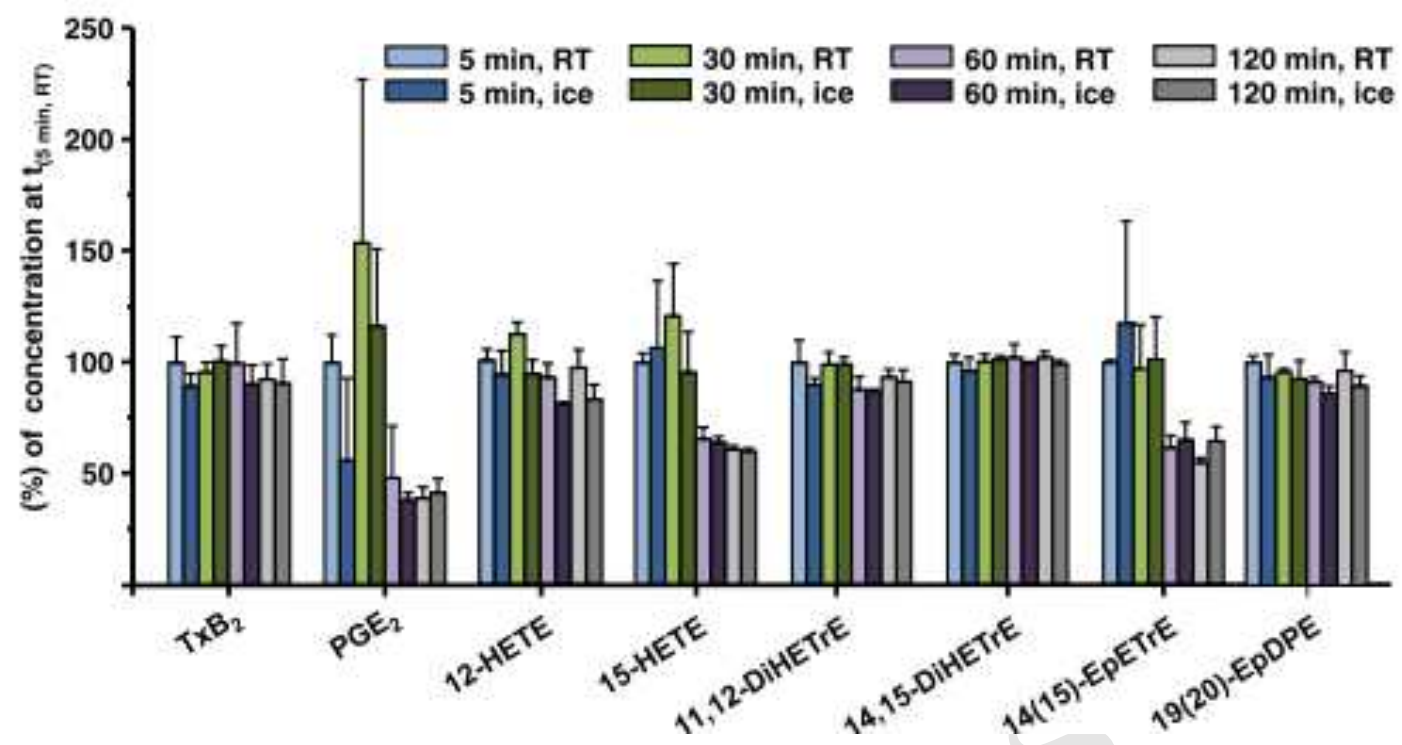

Figure 4. Ex vivo degradation/formation of oxylipins in human whole blood after blood withdrawal. Blood of a healthy human volunteer was collected in EDTA tubes, pooled and left for $5 \mathrm{~min}, 30 \mathrm{~min}$, $60 \mathrm{~min}$ or $120 \mathrm{~min}$ either at room temperature (RT) or on ice. After centrifugation (1200 g, $15 \mathrm{~min}, 4$ $\left.{ }^{\circ} \mathrm{C}\right)$, plasma was immediately frozen $\left(-80^{\circ} \mathrm{C}\right)$ and the oxylipin concentration was analyzed within 5 days. The resulting concentrations after different periods of time in sample preparation are compared to those with direct sample preparation $\left(t_{(5 \mathrm{~min}, \mathrm{RT})}\right)$. The results clearly show, that after 60 min storage of whole blood the levels of several oxylipins are massively reduced (e.g. 15-HETE and 14(15)-EpETrE) while other analytes are formed ex vivo (e.g. $\mathrm{PGE}_{2}$ ). Reprint with permission from (55). 


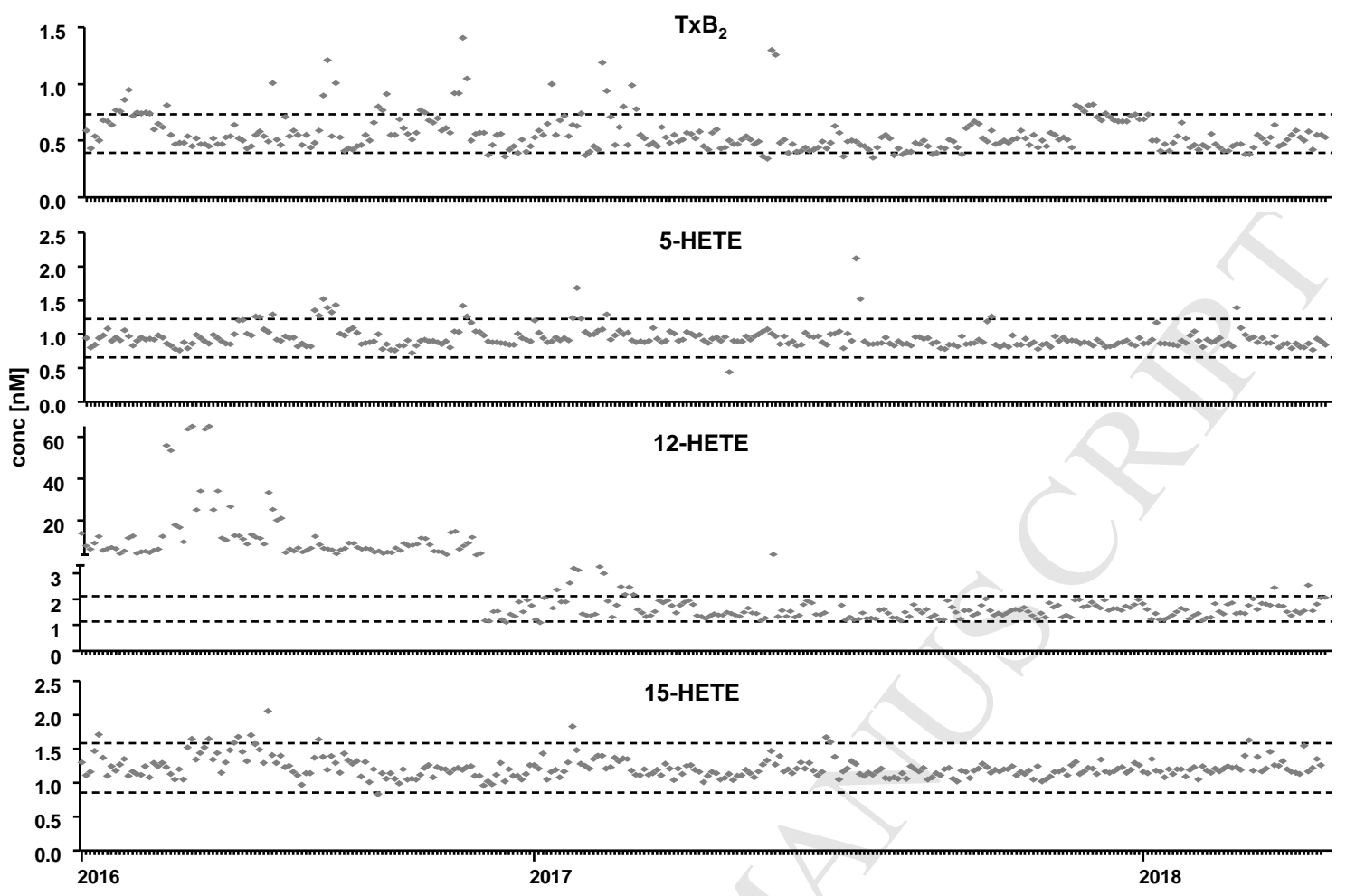

Figure 5. Stability of oxylipins in EDTA plasma during a storage period of two and a half years. EDTA plasma (pooled from healthy subjects, 3 female and 2 male, 25-38 years) was stored in aliquots at -80 ${ }^{\circ} \mathrm{C}$. Shown are absolute concentrations of selected oxylipins in plasma (extraction volume: $500 \mu \mathrm{L}$ ). From January 2016 to August 2018 EDTA plasma was repeatedly prepared using the current standard procedure at the time. Since November 2016, protein precipitation by methanol was carried out prior SPE. The dotted lines indicate the mean concentration $\pm 30 \%$ (determined over 32 months). Oxylipin concentrations were determined as described in (76) till 11/2016 and in 2017-2018 as described in $(4,185)$. 

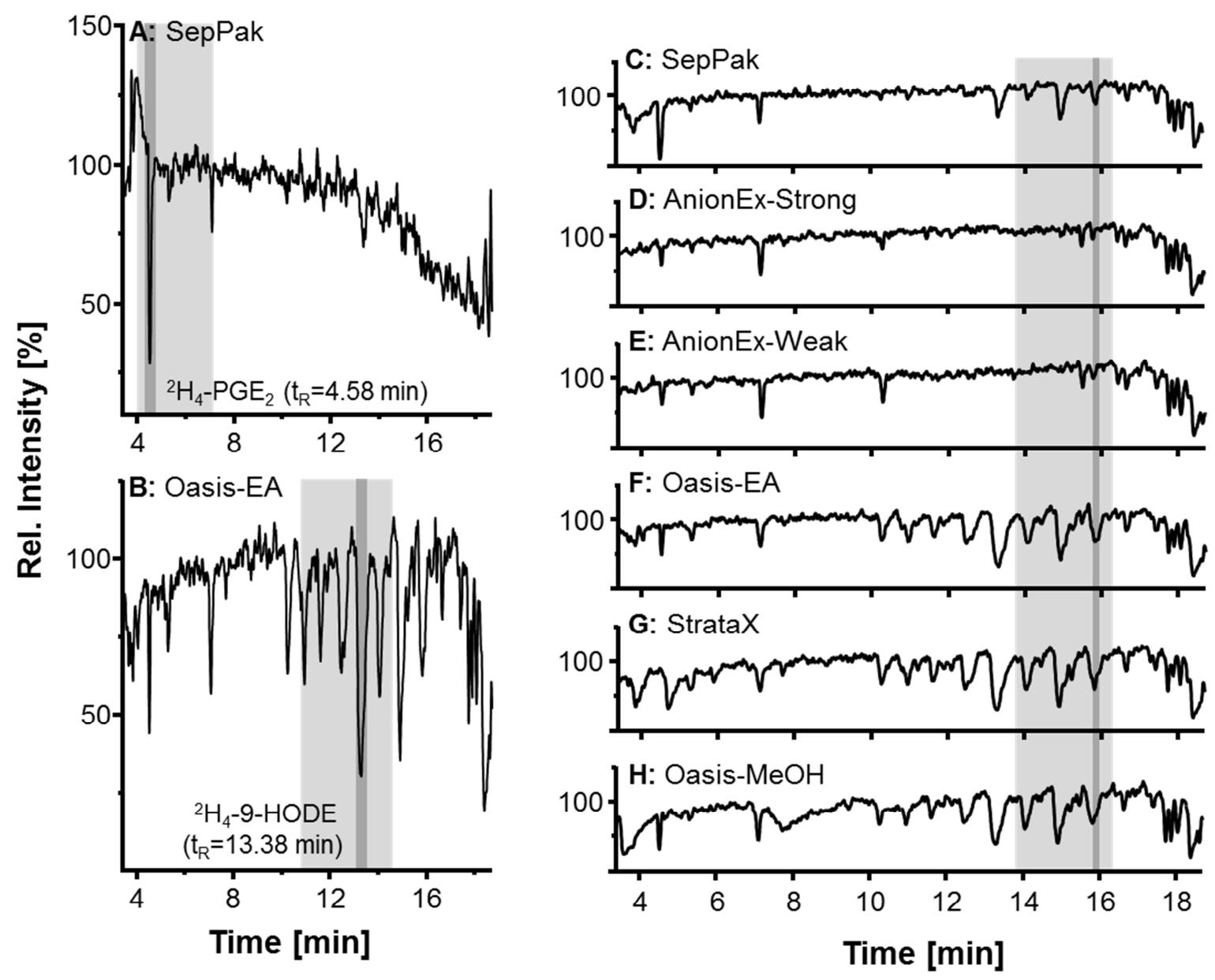

Figure 6. Ion suppression analysis for $(\mathrm{A})^{2} \mathrm{H}_{4}$-PGE2 with SepPak-SPE, (B) ${ }^{2} \mathrm{H}^{4}-9-\mathrm{HODE}$ with the OasisEA-SPE and (C-E) for ${ }^{2} \mathrm{H}_{4}-9(10)$-EpOME with different SPE protocols. The retention time window of each IS is highlighted in dark grey, the elution window of all analytes using this ISTD is depicted in light grey. The different SPE methods are summarized in Ostermann, 2015. Reprint with permission from (76). 

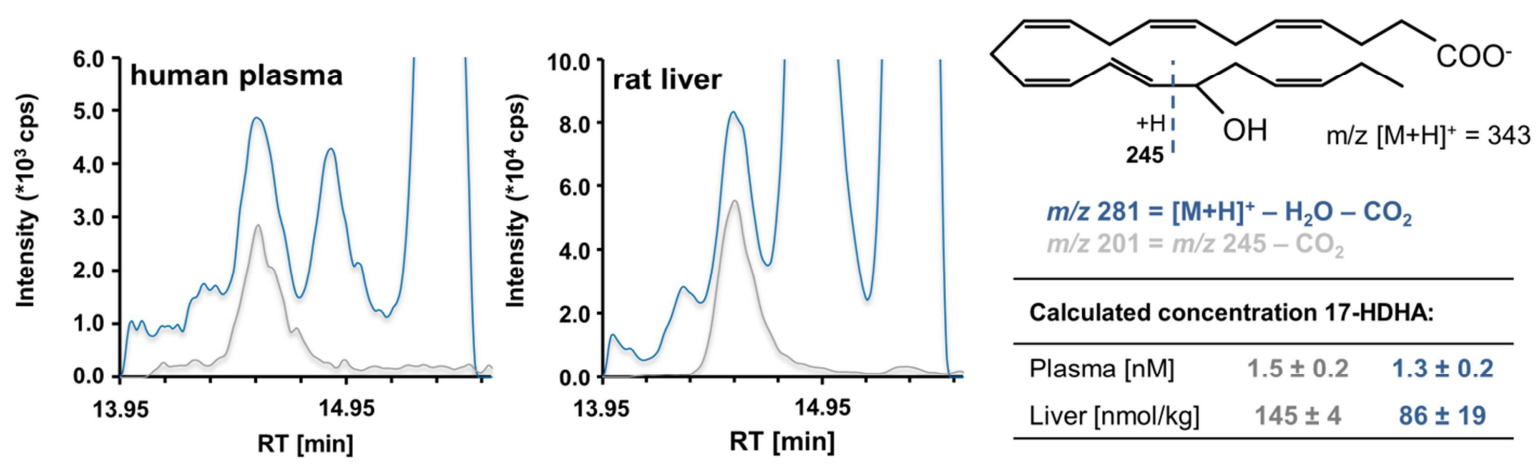

$$
\begin{aligned}
& m / z 281=[\mathrm{M}+\mathrm{H}]^{+}-\mathrm{H}_{2} \mathrm{O}-\mathrm{CO}_{2} \\
& m / z 201=m / z 245-\mathrm{CO}_{2}
\end{aligned}
$$

Calculated concentration 17-HDHA:

\begin{tabular}{lll}
\hline Plasma [nM] & $1.5 \pm 0.2$ & $1.3 \pm 0.2$
\end{tabular}

Liver $[\mathrm{nmol} / \mathrm{kg}] \quad 145 \pm 4 \quad 86 \pm 19$

Figure 7. Quantification of $17-\mathrm{HDHA}$ in human plasma and rat liver tissue using different MStransitions. LC-MS based oxylipin analysis and sample preparation was carried out according to (76). 


\section{References}

1. Buczynski, M. W., Dumlao, D. S., and Dennis, E. A. (2009) Thematic Review Series: Proteomics. An integrated omics analysis of eicosanoid biology. J Lipid Res 50, 1015-1038

2. Rund, K. M., Heylmann, D., Seiwert, N., Wecklein, S., Oger, C., Galano, J., Durand, T., Chen, R., Gueler, F., Fahrer, J., Bornhorst, J., and Schebb, N. H. (2019) Formation of trans-epoxy fatty acids correlates with formation of isoprostanes and could serve as biomarker of oxidative stress. Prostaglandins and Other Lipid Mediators

3. Smith WL, and Murphy RC. (2002) The eicosanoids: cyclooxygenase, lipoxygenase, and epoxygenase pathways. In Biochemistry of Lipids, Lipoproteins and Membranes (4th eds (Vance, D. E. V. a. J. E., ed), Elsevier Science B.V.

4. Rund, K. M., Ostermann, A. I., Kutzner, L., Galano, J. M., Oger, C., Vigor, C., Wecklein, S., Seiwert, N., Durand, T., and Schebb, N. H. (2018) Development of an LC-ESI(-)-MS/MS method for the simultaneous quantification of 35 isoprostanes and isofurans derived from the major n3- and n6-PUFAs. Anal Chim Acta 1037, 63-74

5. Smith, W. L., DeWitt, D. L., and Garavito, R. M. (2000) Cyclooxygenases: structural, cellular, and molecular biology. Annu Rev Biochem 69, 145-182

6. O'Donnell, V. B., and Murphy, R. C. (2017) Directing eicosanoid esterification into phospholipids. Journal of Lipid Research 58, 837-839

7. Park, S. K., Herrnreiter, A., Pfister, S. L., Gauthier, K. M., Falck, B. A., Falck, J. R., and Campbell, W. B. (2018) GPR40 is a low-affinity epoxyeicosatrienoic acid receptor in vascular cells. J Biol Chem 293, 10675-10691

8. Meves, H. (2008) Arachidonic acid and ion channels: an update. Br J Pharmacol 155, 4-16

9. Watanabe, H., Vriens, J., Prenen, J., Droogmans, G., Voets, T., and Nilius, B. (2003) Anandamide and arachidonic acid use epoxyeicosatrienoic acids to activate TRPV4 channels. Nature 424, 434-438

10. Wen, H., Ostman, J., Bubb, K. J., Panayiotou, C., Priestley, J. V., Baker, M. D., and Ahluwalia, A. (2012) 20-Hydroxyeicosatetraenoic acid (20-HETE) is a novel activator of transient receptor potential vanilloid 1 (TRPV1) channel. J Biol Chem 287, 13868-13876

11. Bos, C. L., Richel, D. J., Ritsema, T., Peppelenbosch, M. P., and Versteeg, H. H. (2004) Prostanoids and prostanoid receptors in signal transduction. Int J Biochem Cell Biol 36, 11871205

12. Hardwick, J. P., Eckman, K., Lee, Y. K., Abdelmegeed, M. A., Esterle, A., Chilian, W. M., Chiang, J. Y., and Song, B. J. (2013) Eicosanoids in metabolic syndrome. Adv Pharmacol 66, 157-266

13. Bosviel, R., Joumard-Cubizolles, L., Chinetti-Gbaguidi, G., Bayle, D., Copin, C., Hennuyer, N., Duplan, I., Staels, B., Zanoni, G., Porta, A., Balas, L., Galano, J. M., Oger, C., Mazur, A., Durand, T., and Gladine, C. (2017) DHA-derived oxylipins, neuroprostanes and protectins, differentially and dose-dependently modulate the inflammatory response in human macrophages: Putative mechanisms through PPAR activation. Free Radic Biol Med 103, 146154

14. Brooks, J. D., Musiek, E. S., Koestner, T. R., Stankowski, J. N., Howard, J. R., Brunoldi, E. M., Porta, A., Zanoni, G., Vidari, G., Morrow, J. D., Milne, G. L., and McLaughlin, B. (2011) The fatty acid oxidation product 15-A3t-isoprostane is a potent inhibitor of NFkappaB transcription and macrophage transformation. J Neurochem 119, 604-616

15. Musiek, E. S., Brooks, J. D., Joo, M., Brunoldi, E., Porta, A., Zanoni, G., Vidari, G., Blackwell, T. S., Montine, T. J., Milne, G. L., McLaughlin, B., and Morrow, J. D. (2008) Electrophilic cyclopentenone neuroprostanes are anti-inflammatory mediators formed from the peroxidation of the omega-3 polyunsaturated fatty acid docosahexaenoic acid. I Biol Chem 283, 19927-19935 
16. Tatsuno, I., Saito, H., Chang, K. J., Tamura, Y., and Yoshida, S. (1990) Comparison of the effect between leukotriene B4 and leukotriene B5 on the induction of interleukin 1-like activity and calcium mobilizing activity in human blood monocytes. Agents Actions 29, 324-327

17. Ulu, A., Stephen Lee, K. S., Miyabe, C., Yang, J., Hammock, B. G., Dong, H., and Hammock, B. D. (2014) An omega-3 epoxide of docosahexaenoic acid lowers blood pressure in angiotensin-II-dependent hypertension. J Cardiovasc Pharmacol 64, 87-99

18. Lotzer, K., Jahn, S., Kramer, C., Hildner, M., Nusing, R., Funk, C. D., and Habenicht, A. J. (2007) 5-Lipoxygenase/cyclooxygenase-2 cross-talk through cysteinyl leukotriene receptor 2 in endothelial cells. Prostaglandins Other Lipid Mediat 84, 108-115

19. Oni-Orisan, A., Deng, Y., Schuck, R. N., Theken, K. N., Edin, M. L., Lih, F. B., Molnar, K., DeGraff, L., Tomer, K. B., Zeldin, D. C., and Lee, C. R. (2013) Dual modulation of cyclooxygenase and CYP epoxygenase metabolism and acute vascular inflammation in mice. Prostaglandins Other Lipid Mediat 104-105, 67-73

20. Rouzer, C. A., and Marnett, L. J. (2011) Endocannabinoid oxygenation by cyclooxygenases, lipoxygenases, and cytochromes P450: cross-talk between the eicosanoid and endocannabinoid signaling pathways. Chem Rev 111, 5899-5921

21. Yeung, J., Hawley, M., and Holinstat, M. (2017) The expansive role of oxylipins on platelet biology. J Mol Med (Berl) 95, 575-588

22. Lee, I. T., Lin, C. C., Lin, W. N., Wu, W. L., Hsiao, L. D., and Yang, C. M. (2013) Lung inflammation caused by adenosine-5'-triphosphate is mediated via Ca2+/PKCs-dependent COX-2/PGE2 induction. Int J Biochem Cell Biol 45, 1657-1668

23. Shinomiyaa Shiho, Hiroaki, N., Akinori, U., Iku, U., Takayuki, M., Shuichi, O., Fumitaka, U., Koichi, Y., Shuh, N., Yukihiko, S., Atsushi, I., and Sachiko, O.-i. (2001) Regulation of TNFa and interleukin-10 production by prostaglandins 12 and E2: studies with prostaglandin receptordeficient mice and prostaglandin E-receptor subtype-selective synthetic agonists. Biochemical Pharmacology 61 1153-1160

24. Urade, Y., and Eguchi, N. (2002) Lipocalin-type and hematopoietic prostaglandin D synthases as a novel example of functional convergence. Prostaglandins \& Other Lipid Mediators 68-69, 375-382

25. Rajakariar, R., Hilliard, M., Lawrence, T., Trivedi, S., Colville-Nash, P., Bellingan, G., Fitzgerald, D., Yaqoob, M. M., and Gilroy, D. W. (2007) Hematopoietic prostaglandin D2 synthase controls the onset and resolution of acute inflammation through PGD2 and 15-deoxyDelta12 14 PGJ2. Proc Natl Acad Sci U S A 104, 20979-20984

26. Funk, C. D. (2001) Prostaglandins and leukotrienes: advances in eicosanoid biology. Science 294, 1871-1875

27. Ueno, N., Murakami, M., Tanioka, T., Fujimori, K., Tanabe, T., Urade, Y., and Kudo, I. (2001) Coupling between cyclooxygenase, terminal prostanoid synthase, and phospholipase A2. J Biol Chem 276, 34918-34927

28. Li, Y., Lei, D., Swindell, W. R., Xia, W., Weng, S., Fu, J., Worthen, C. A., Okubo, T., Johnston, A., Gudjonsson, J. E., Voorhees, J. J., and Fisher, G. J. (2015) Age-Associated Increase in Skin Fibroblast-Derived Prostaglandin E2 Contributes to Reduced Collagen Levels in Elderly Human Skin. J Invest Dermatol 135, 2181-2188

29. Farhat, A., Philibert, P., Sultan, C., Poulat, F., and Boizet-Bonhoure, B. (2011) HematopoieticProstaglandin D2 synthase through PGD2 production is involved in the adult ovarian physiology. J Ovarian Res 4, 3

30. Shureiqi, I. (2000) 15-LOX-1: a Novel Molecular Target of Nonsteroidal Anti-inflammatory Drug-Induced Apoptosis in Colorectal Cancer Cells. Journal of the National Cancer Institute 92, 1136-1142

31. Kuhn, H., Banthiya, S., and van Leyen, K. (2015) Mammalian lipoxygenases and their biological relevance. Biochimica et Biophysica Acta 1851, 308-330 
32. Kutzner, L., Goloshchapova, K., Heydeck, D., Stehling, S., Kuhn, H., and Schebb, N. H. (2017) Mammalian ALOX15 orthologs exhibit pronounced dual positional specificity with docosahexaenoic acid. Biochim Biophys Acta Mol Cell Biol Lipids 1862, 666-675

33. Jamieson, K. L., Endo, T., Darwesh, A. M., Samokhvalov, V., and Seubert, J. M. (2017) Cytochrome P450-derived eicosanoids and heart function. Pharmacol Ther 179, 47-83

34. Westphal, C., Konkel, A., and Schunck, W. H. (2015) Cytochrome p450 enzymes in the bioactivation of polyunsaturated Fatty acids and their role in cardiovascular disease. Adv Exp Med Biol 851, 151-187

35. Schebb, N. H., Ostermann, A. I., Yang, J., Hammock, B. D., Hahn, A., and Schuchardt, J. P. (2014) Comparison of the effects of long-chain omega-3 fatty acid supplementation on plasma levels of free and esterified oxylipins. Prostaglandins Other Lipid Mediat 113-115, 2129

36. Shearer, G. C., and Newman, J. W. (2008) Lipoprotein lipase releases esterified oxylipins from very low-density lipoproteins. Prostaglandins, Leukotrienes and Essential Fatty Acids 79, 215222

37. Ek-Von Mentzer, B. A., Zhang, F., and Hamilton, J. A. (2001) Binding of 13-HODE and 15-HETE to phospholipid bilayers, albumin, and intracellular fatty acid binding proteins. implications for transmembrane and intracellular transport and for protection from lipid peroxidation. $J$ Biol Chem 276, 15575-15580

38. Maclouf, J., Kindahl, H., Granstrom, E., and Samuelsson, B. (1980) Interactions of prostaglandin $\mathrm{H} 2$ and thromboxane A2 with human serum albumin. Eur J Biochem 109, 561 566

39. Boilard, E. (2018) Extracellular vesicles and their content in bioactive lipid mediators: more than a sack of microRNA. J Lipid Res 59, 2037-2046

40. Wopereis, S., Wolvers, D., van Erk, M., Gribnau, M., Kremer, B., van Dorsten, F. A., Boelsma, E., Garczarek, U., Cnubben, N., Frenken, L., van der Logt, P., Hendriks, H. F., Albers, R., van Duynhoven, J., van Ommen, B., and Jacobs, D. M. (2013) Assessment of inflammatory resilience in healthy subjects using dietary lipid and glucose challenges. BMC Med Genomics 6, 44

41. Ostermann, A. I., Greupner, T., Kutzner, L., Hartung, Nicole M., Hahn, A., Schuchardt, J. P., and Schebb, N. H. (2018) Intra-individual variance of the human plasma oxylipin pattern: low inter-day variability in fasting blood samples versus high variability during the day. Analytical Methods 10, 4935-4944

42. Kamleh, M. A., McLeod, O., Checa, A., Baldassarre, D., Veglia, F., Gertow, K., Humphries, S. E., Rauramaa, R., de Faire, U., Smit, A. J., Giral, P., Kurl, S., Mannarino, E., Tremoli, E., Silveira, A., Orvik, J., Hamsten, A., and Wheelock, C. E. (2018) Increased Levels of Circulating Fatty Acids Are Associated with Protective Effects against Future Cardiovascular Events in Nondiabetics. $J$ Proteome Res 17, 870-878

43. Sun, Y., Koh, H. W., Choi, H., Koh, W. P., Yuan, J. M., Newman, J. W., Su, J., Fang, J., Ong, C. N., and van Dam, R. M. (2016) Plasma fatty acids, oxylipins, and risk of myocardial infarction: the Singapore Chinese Health Study. J Lipid Res 57, 1300-1307

44. Hammond, V. J., and O'Donnell, V. B. (2012) Esterified eicosanoids: generation, characterization and function. Biochim Biophys Acta 1818, 2403-2412

45. Shearer, G. C., Borkowski, K., Puumala, S. L., Harris, W. S., Pedersen, T. L., and Newman, J. W. (2018) Abnormal lipoprotein oxylipins in metabolic syndrome and partial correction by omega-3 fatty acids. Prostaglandins Leukot Essent Fatty Acids 128, 1-10

46. Milne, G. L., Yin, H., and Morrow, J. D. (2008) Human biochemistry of the isoprostane pathway. J Biol Chem 283, 15533-15537

47. Dalle, C., Ostermann, A. I., Konrad, T., Coudy-Gandilhon, C., Decourt, A., Barthelemy, J. C., Roche, F., Feasson, L., Mazur, A., Bechet, D., Schebb, N. H., and Gladine, C. (2018) Muscle loss associated changes of oxylipin signatures during biological aging: an exploratory study from the PROOF cohort. J Gerontol A Biol Sci Med Sci 
48. Greupner, T., Kutzner, L., Nolte, F., Strangmann, A., Kohrs, H., Hahn, A., Schebb, N. H., and Schuchardt, J. P. (2018) Effects of a 12-week high-alpha-linolenic acid intervention on EPA and DHA concentrations in red blood cells and plasma oxylipin pattern in subjects with a low EPA and DHA status. Food Funct 9, 1587-1600

49. Keenan, A. H., Pedersen, T. L., Fillaus, K., Larson, M. K., Shearer, G. C., and Newman, J. W. (2012) Basal omega-3 fatty acid status affects fatty acid and oxylipin responses to high-dose n3-HUFA in healthy volunteers. J Lipid Res 53, 1662-1669

50. Caligiuri, S. P., Aukema, H. M., Ravandi, A., and Pierce, G. N. (2014) Elevated levels of proinflammatory oxylipins in older subjects are normalized by flaxseed consumption. Exp Gerontol 59, 51-57

51. Song, J., Liu, X., Rao, T. S., Chang, L., Meehan, M. J., Blevitt, J. M., Wu, J., Dorrestein, P. C., and Milla, M. E. (2015) Phenotyping drug polypharmacology via eicosanoid profiling of blood. Journal of Lipid Research 56

52. Ostermann, A. I., and Schebb, N. H. (2017) Effects of omega-3 fatty acid supplementation on the pattern of oxylipins: a short review about the modulation of hydroxy-, dihydroxy-, and epoxy-fatty acids. Food Funct 8, 2355-2367

53. Arita, M. (2012) Mediator lipidomics in acute inflammation and resolution. J Biochem 152, 313-319

54. Roberts, L. D., Souza, A. L., Gerszten, R. E., and Clish, C. B. (2012) Targeted metabolomics. Curr Protoc Mol Biol Chapter 30, Unit 3032 31-24

55. Willenberg, I., Rund, K., Rong, S., Shushakova, N., Gueler, F., and Schebb, N. H. (2015) Characterization of changes in plasma and tissue oxylipin levels in LPS and CLP induced murine sepsis. Inflammation Research 65, 133-142

56. Ostermann, A. I., Waindok, P., Schmidt, M. J., Chiu, C. Y., Smyl, C., Rohwer, N., Weylandt, K. H., and Schebb, N. H. (2017) Modulation of the endogenous omega-3 fatty acid and oxylipin profile in vivo-A comparison of the fat- 1 transgenic mouse with C57BL/ 6 wildtype mice on an omega-3 fatty acid enriched diet. PLoS One 12, e0184470

57. Jonasdottir, H. S., Brouwers, H., Toes, R. E. M., loan-Facsinay, A., and Giera, M. (2018) Effects of anticoagulants and storage conditions on clinical oxylipid levels in human plasma. Biochim Biophys Acta Mol Cell Biol Lipids 1863, 1511-1522

58. Schuchardt, J. P., Schmidt, S., Kressel, G., Dong, H., Willenberg, I., Hammock, B. D., Hahn, A., and Schebb, N. H. (2013) Comparison of free serum oxylipin concentrations in hyper- vs. normolipidemic men. Prostaglandins Leukot Essent Fatty Acids 89, 19-29

59. La Frano, M. R., Carmichael, S. L., Ma, C., Hardley, M., Shen, T., Wong, R., Rosales, L., Borkowski, K., Pedersen, T. L., Shaw, G. M., Stevenson, D. K., Fiehn, O., and Newman, J. W. (2018) Impact of post-collection freezing delay on the reliability of serum metabolomics in samples reflecting the California mid-term pregnancy biobank. Metabolomics 14

60. Dorow, J., Becker, S., Kortz, L., Thiery, J., Hauschildt, S., and Ceglarek, U. (2016) Preanalytical Investigation of Polyunsaturated Fatty Acids and Eicosanoids in Human Plasma by Liquid Chromatography-Tandem Mass Spectrometry. Biopreservation and Biobanking 14, 107-113

61. Goodfriend, T. L., Pedersen, T. L., Grekin, R. J., Hammock, B. D., Ball, D. L., and Vollmer, A. (2007) Heparin, lipoproteins, and oxygenated fatty acids in blood: a cautionary note. Prostaglandins Leukot Essent Fatty Acids 77, 363-366

62. Nakamura, H., Kim, D. K., Philbin, D. M., Peterson, M. B., Debros, F., Koski, G., and Bonventre, J. V. (1995) Heparin-enhanced plasma phospholipase A2 activity and prostacyclin synthesis in patients undergoing cardiac surgery. J Clin Invest 95, 1062-1070

63. Strassburg, K., Huijbrechts, A. M. L., Kortekaas, K. A., Lindeman, J. H., Pedersen, T. L., Dane, A., Berger, R., Brenkman, A., Hankemeier, T., van Duynhoven, J., Kalkhoven, E., Newman, J. W., and Vreeken, R. J. (2012) Quantitative profiling of oxylipins through comprehensive LCMS/MS analysis: application in cardiac surgery. Analytical and Bioanalytical Chemistry 404, 1413-1426

64. Goodall, A. H. (2014) Platelet 12-LOX scores a HIT. Blood 124, 2166-2168 
65. Gladine, C., Newman, J. W., Durand, T., Pedersen, T. L., Galano, J. M., Demougeot, C., Berdeaux, O., Pujos-Guillot, E., Mazur, A., and Comte, B. (2014) Lipid profiling following intake of the omega 3 fatty acid DHA identifies the peroxidized metabolites F4neuroprostanes as the best predictors of atherosclerosis prevention. PLoS One 9, e89393

66. Dupuy, A., Le Faouder, P., Vigor, C., Oger, C., Galano, J. M., Dray, C., Lee, J. C., Valet, P., Gladine, C., Durand, T., and Bertrand-Michel, J. (2016) Simultaneous quantitative profiling of 20 isoprostanoids from omega-3 and omega- 6 polyunsaturated fatty acids by LC-MS/MS in various biological samples. Anal Chim Acta 921, 46-58

67. Quehenberger, O., Dahlberg-Wright, S., Jiang, J., Armando, A. M., and Dennis, E. A. (2018) Quantitative determination of esterified eicosanoids and related oxygenated metabolites after base hydrolysis. J Lipid Res 59, 2436-2445

68. Newman, J. W., Kaysen, G. A., Hammock, B. D., and Shearer, G. C. (2007) Proteinuria increases oxylipid concentrations in VLDL and HDL but not LDL particles in the rat. J Lipid Res 48, $1792-1800$

69. Arnold, C., Markovic, M., Blossey, K., Wallukat, G., Fischer, R., Dechend, R., Konkel, A., von Schacky, C., Luft, F. C., Muller, D. N., Rothe, M., and Schunck, W.-H. (2010) Arachidonic Acidmetabolizing Cytochrome P450 Enzymes Are Targets of $\omega-3$ Fatty Acids. Journal of Biological Chemistry 285, 32720-32733

70. Duflot, T., Pereira, T., Roche, C., lacob, M., Cardinael, P., Hamza, N. E., Thuillez, C., Compagnon, P., Joannides, R., Lamoureux, F., and Bellien, J. (2017) A sensitive LC-MS/MS method for the quantification of regioisomers of epoxyeicosatrienoic and dihydroxyeicosatrienoic acids in human plasma during endothelial stimulation. Anal Bioanal Chem 409, 1845-1855

71. Morisseau, C., Inceoglu, B., Schmelzer, K., Tsai, H.-J., Jinks, S. L., Hegedus, C. M., and Hammock, B. D. (2010) Naturally occurring monoepoxides of eicosapentaenoic acid and docosahexaenoic acid are bioactive antihyperalgesic lipids. Journal of Lipid Research 51, 3481-3490

72. Dumlao, D. S., Buczynski, M. W., Norris, P. C., Harkewicz, R., and Dennis, E. A. (2011) Highthroughput lipidomic analysis of fatty acid derived eicosanoids and $\mathrm{N}$-acylethanolamines. Biochim Biophys Acta 1811, 724-736

73. Arnold, C., Markovic, M., Blossey, K., Wallukat, G., Fischer, R., Dechend, R., Konkel, A., von Schacky, C., Luft, F. C., Muller, D. N., Rothe, M., and Schunck, W. H. (2010) Arachidonic acidmetabolizing cytochrome P450 enzymes are targets of \{omega\}-3 fatty acids. $J$ Biol Chem 285, 32720-32733

74. Yang, J., Schmelzer, K., Georgi, K., and Hammock, B. D. (2009) Quantitative profiling method for oxylipin metabolome by liquid chromatography electrospray ionization tandem mass spectrometry. Anal Chem 81, 8085-8093

75. Giera, M., Ioan-Facsinay, A., Toes, R., Gao, F., Dalli, J., Deelder, A. M., Serhan, C. N., and Mayboroda, O. A. (2012) Lipid and lipid mediator profiling of human synovial fluid in rheumatoid arthritis patients by means of LC-MS/MS. Biochim Biophys Acta 1821, 1415-1424

76. Ostermann, A. I., Willenberg, I., and Schebb, N. H. (2015) Comparison of sample preparation methods for the quantitative analysis of eicosanoids and other oxylipins in plasma by means of LC-MS/MS. Anal Bioanal Chem 407, 1403-1414

77. Pedersen, T. L., and Newman, J. W. (2018) Establishing and Performing Targeted Multiresidue Analysis for Lipid Mediators and Fatty Acids in Small Clinical Plasma Samples. Methods Mol Biol 1730, 175-212

78. Fromel, T., Jungblut, B., Hu, J., Trouvain, C., Barbosa-Sicard, E., Popp, R., Liebner, S., Dimmeler, S., Hammock, B. D., and Fleming, I. (2012) Soluble epoxide hydrolase regulates hematopoietic progenitor cell function via generation of fatty acid diols. Proc Natl Acad Sci U S A 109, 9995-10000

79. Ferreirós, N., Homann, J., Labocha, S., Grossmann, N., Hahn, J. S., Brüne, B., and Geisslinger, G. (2014) Lipoxin A4: Problems with its determination using reversed phase 
chromatography-tandem mass spectrometry and confirmation with chiral chromatography. Talanta 127, 82-87

80. Stahnke, H., Reemtsma, T., and Alder, L. (2009) Compensation of matrix effects by postcolumn infusion of a monitor substance in multiresidue analysis with LC-MS/MS. Anal Chem 81, 2185-2192

81. Campbell, W. B., Falck, J. R., Okita, J. R., Johnson, A. R., and Callahan, K. S. (1985) Synthesis of dihomoprostaglandins from adrenic acid (7,10,13,16-docosatetraenoic acid) by human endothelial cells. Biochim Biophys Acta 837, 67-76

82. Kopf, P. G., Zhang, D. X., Gauthier, K. M., Nithipatikom, K., Yi, X. Y., Falck, J. R., and Campbell, W. B. (2010) Adrenic acid metabolites as endogenous endothelium-derived and zona glomerulosa-derived hyperpolarizing factors. Hypertension 55, 547-554

83. Markworth, J. F., Kaur, G., Miller, E. G., Larsen, A. E., Sinclair, A. J., Maddipati, K. R., and Cameron-Smith, D. (2016) Divergent shifts in lipid mediator profile following supplementation with n-3 docosapentaenoic acid and eicosapentaenoic acid. FASEB J 30, 3714-3725

84. Bhattacharjee, S., Jun, B., Belayev, L., Heap, J., Kautzmann, M. A., Obenaus, A., Menghani, H., Marcell, S. J., Khoutorova, L., Yang, R., Petasis, N. A., and Bazan, N. G. (2017) Elovanoids are a novel class of homeostatic lipid mediators that protect neural cell integrity upon injury. Sci Adv 3, e1700735

85. Berkecz, R., Lisa, M., and Holcapek, M. (2017) Analysis of oxylipins in human plasma: Comparison of ultrahigh-performance liquid chromatography and ultrahigh-performance supercritical fluid chromatography coupled to mass spectrometry. J Chromatogr A 1511, 107121

86. Meckelmann, S. W., Hellhake, S., Steuck, M., Krohn, M., and Schebb, N. H. (2017) Comparison of derivatization/ionization techniques for liquid chromatography tandem mass spectrometry analysis of oxylipins. Prostaglandins Other Lipid Mediat 130, 8-15

87. Newman, J. W., Watanabe, T., and Hammock, B. D. (2002) The simultaneous quantification of cytochrome P450 dependent linoleate and arachidonate metabolites in urine by HPLCMS/MS. J Lipid Res 43, 1563-1578

88. Watrous, J. D., Niiranen, T. J., Lagerborg, K. A., Henglin, M., Xu, Y. J., Rong, J., Sharma, S., Vasan, R. S., Larson, M. G., Armando, A., Mora, S., Quehenberger, O., Dennis, E. A., Cheng, S., and Jain, M. (2019) Directed Non-targeted Mass Spectrometry and Chemical Networking for Discovery of Eicosanoids and Related Oxylipins. Cell Chem Biol

89. Aoyagi, R., Ikeda, K., Isobe, Y., and Arita, M. (2017) Comprehensive analyses of oxidized phospholipids using a measured MS/MS spectra library. J Lipid Res 58, 2229-2237

90. Willenberg, I., Ostermann, A. I., and Schebb, N. H. (2015) Targeted metabolomics of the arachidonic acid cascade: current state and challenges of LC-MS analysis of oxylipins. Anal Bioanal Chem 407, 2675-2683

91. Jonasdottir, H. S., Papan, C., Fabritz, S., Balas, L., Durand, T., Hardardottir, I., Freysdottir, J., and Giera, M. (2015) Differential mobility separation of leukotrienes and protectins. Anal Chem 87, 5036-5040

92. Roy, U., Loreau, O., and Balazy, M. (2004) Cytochrome P450/NADPH-dependent formation of trans epoxides from trans-arachidonic acids. Bioorg Med Chem Lett 14, 1019-1022

93. Balazy, M., and Chemtob, S. (2008) Trans-arachidonic acids: new mediators of nitro-oxidative stress. Pharmacol Ther 119, 275-290

94. Adkins, Y., Belda, B. J., Pedersen, T. L., Fedor, D. M., Mackey, B. E., Newman, J. W., and Kelley, D. S. (2017) Dietary Docosahexaenoic Acid and trans-10, cis-12-Conjugated Linoleic Acid Differentially Alter Oxylipin Profiles in Mouse Periuterine Adipose Tissue. Lipids 52, 399413

95. Lee, S. H., Williams, M. V., and Blair, I. A. (2005) Targeted chiral lipidomics analysis. Prostaglandins Other Lipid Mediat 77, 141-157 
96. Mesaros, C., Lee, S. H., and Blair, I. A. (2009) Targeted quantitative analysis of eicosanoid lipids in biological samples using liquid chromatography-tandem mass spectrometry. $J$ Chromatogr B Analyt Technol Biomed Life Sci 877, 2736-2745

97. Karara, A., Dishman, E., Blair, I., Falck, J. R., and Capdevila, J. H. (1989) Endogenous epoxyeicosatrienoic acids: Cytochrome P-450 controlled stereoselectivity of the hepatic arachidonic acid epoxygenase. J. Biol. Chem. 264, 19855-19827

98. Fuchs, D., Hamberg, M., Skold, C. M., Wheelock, A. M., and Wheelock, C. E. (2018) An LC$\mathrm{MS} / \mathrm{MS}$ workflow to characterize 16 regio- and stereoisomeric trihydroxyoctadecenoic acids. J Lipid Res 59, 2025-2033

99. Mazaleuskaya, L. L., Salamatipour, A., Sarantopoulou, D., Weng, L., FitzGerald, G. A., Blair, I. A., and Mesaros, C. (2018) Analysis of HETEs in human whole blood by chiral UHPLCECAPCI/HRMS. J Lipid Res 59, 564-575

100. Mesaros, C., and Blair, I. A. (2012) Targeted chiral analysis of bioactive arachidonic Acid metabolites using liquid-chromatography-mass spectrometry. Metabolites 2, 337-365

101. Blum, M., Dogan, I., Karber, M., Rothe, M., and Schunck, W. H. (2019) Chiral lipidomics of monoepoxy and monohydroxy metabolites derived from long-chain polyunsaturated fatty acids. J Lipid Res 60, 135-148

102. Oh, S. F., Vickery, T. W., and Serhan, C. N. (2011) Chiral lipidomics of E-series resolvins: aspirin and the biosynthesis of novel mediators. Biochim Biophys Acta 1811, 737-747

103. Falgueyret, J. P., Leblanc, Y., Rokach, J., and Riendeau, D. (1988) NAD(P)H-dependent reduction of 12-ketoeicosatetraenoic acid to $12(\mathrm{R})$ - and 12(S)-hydroxyeicosatetraenoic acid by rat liver microsomes. Biochem Biophys Res Commun 156, 1083-1089

104. Boeglin, W. E., Kim, R. B., and Brash, A. R. (1998) A 12R-lipoxygenase in human skin: mechanistic evidence, molecular cloning, and expression. Proc Natl Acad Sci U S A 95, 67446749

105. Homann, J., Lehmann, C., Kahnt, A. S., Steinhilber, D., Parnham, M. J., Geisslinger, G., and Ferreiros, N. (2014) Chiral chromatography-tandem mass spectrometry applied to the determination of pro-resolving lipid mediators. J Chromatogr A 1360, 150-163

106. Hartung, N. M., Mainka, M., Kampschulte, N., Ostermann, A. I., and Schebb, N. H. (2019) A strategy for validating concentrations of oxylipin standards for external calibration. Prostaglandins Other Lipid Mediat 141, 22-24

107. Chocholouskova, M., Jirasko, R., Vrana, D., Gatek, J., Melichar, B., and Holcapek, M. (2019) Reversed phase UHPLC/ESI-MS determination of oxylipins in human plasma: a case study of female breast cancer. Anal Bioanal Chem 411, 1239-1251

108. D, M., WB, C., and al., e. (1980) Guidelines for Data Acquisition and Data Quality Evaluation in Environmental Chemistry. Analytical Chemistry 52, 2242-2249

109. Dong, Y., and Peng, C. Y. (2013) Principled missing data methods for researchers. Springerplus 2, 222

110. Helsel, D. (2010) Much ado about next to nothing: incorporating nondetects in science. Ann Occup Hyg 54, 257-262

111. Ogden, T. L. (2010) Handling results below the level of detection. Ann Occup Hyg 54, 255-256

112. Thomas, C. P., Morgan, L. T., Maskrey, B. H., Murphy, R. C., Kuhn, H., Hazen, S. L., Goodall, A. H., Hamali, H. A., Collins, P. W., and O'Donnell, V. B. (2010) Phospholipid-esterified eicosanoids are generated in agonist-activated human platelets and enhance tissue factordependent thrombin generation. J Biol Chem 285, 6891-6903

113. O'Donnell, V. B., and Murphy, R. C. (2012) New families of bioactive oxidized phospholipids generated by immune cells: identification and signaling actions. Blood 120, 1985-1992

114. Klett, E. L., Chen, S., Yechoor, A., Lih, F. B., and Coleman, R. A. (2017) Long-chain acyl-CoA synthetase isoforms differ in preferences for eicosanoid species and long-chain fatty acids. $J$ Lipid Res 58, 884-894 
115. Abbott, S. K., Else, P. L., Atkins, T. A., and Hulbert, A. J. (2012) Fatty acid composition of membrane bilayers: importance of diet polyunsaturated fat balance. Biochim Biophys Acta 1818, 1309-1317

116. Arterburn, L. M., Hall, E. B., and Oken, H. (2006) Distribution, interconversion, and dose response of $\mathrm{n}-3$ fatty acids in humans. Am J Clin Nutr 83, 1467S-1476S

117. Browning, L. M., Walker, C. G., Mander, A. P., West, A. L., Madden, J., Gambell, J. M., Young, S., Wang, L., Jebb, S. A., and Calder, P. C. (2012) Incorporation of eicosapentaenoic and docosahexaenoic acids into lipid pools when given as supplements providing doses equivalent to typical intakes of oily fish. Am J Clin Nutr 96, 748-758

118. Flock, M. R., Skulas-Ray, A. C., Harris, W. S., Etherton, T. D., Fleming, J. A., and Kris-Etherton, P. M. (2013) Determinants of erythrocyte omega-3 fatty acid content in response to fish oil supplementation: a dose-response randomized controlled trial. J Am Heart Assoc 2, e000513

119. Calder, P. C. (2015) Marine omega-3 fatty acids and inflammatory processes: Effects, mechanisms and clinical relevance. Biochimica et Biophysica Acta (BBA)-Molecular and Cell Biology of Lipids 1851, 469-484

120. Strokin, M., Sergeeva, M., and Reiser, G. (2003) Docosahexaenoic acid and arachidonic acid release in rat brain astrocytes is mediated by two separate isoforms of phospholipase $A 2$ and is differently regulated by cyclic AMP and Ca2+. Br J Pharmacol 139, 1014-1022

121. Wada, M., DeLong, C. J., Hong, Y. H., Rieke, C. J., Song, I., Sidhu, R. S., Yuan, C., Warnock, M., Schmaier, A. H., Yokoyama, C., Smyth, E. M., Wilson, S. J., FitzGerald, G. A., Garavito, R. M., Sui de, X., Regan, J. W., and Smith, W. L. (2007) Enzymes and receptors of prostaglandin pathways with arachidonic acid-derived versus eicosapentaenoic acid-derived substrates and products. J Biol Chem 282, 22254-22266

122. Konkel, A., and Schunck, W. H. (2011) Role of cytochrome P450 enzymes in the bioactivation of polyunsaturated fatty acids. Biochim Biophys Acta 1814, 210-222

123. Fischer, R., Konkel, A., Mehling, H., Blossey, K., Gapelyuk, A., Wessel, N., von Schacky, C., Dechend, R., Muller, D. N., Rothe, M., Luft, F. C., Weylandt, K., and Schunck, W. H. (2014) Dietary omega-3 fatty acids modulate the eicosanoid profile in man primarily via the CYPepoxygenase pathway. J Lipid Res 55, 1150-1164

124. Ostermann Al, West AL, Schoenfeld K, Browning LM, Walker CG, Jebb SA, PC, C., and NH, S. (2019) Plasma oxylipins respond in a linear dose-response manner with increased intake of EPA and DHA: results from a randomized controlled trial in healthy humans. American Journal of Clinical Nutrition 109

125. Brune, K., and Patrignani, P. (2015) New insights into the use of currently available nonsteroidal anti-inflammatory drugs. . J Pain Res 8, 105-118

126. Martinez, J. A., Yang, J., Wertheim, B. C., Roe, D. J., Schriewer, A., Lance, P., Alberts, D. S., Hammock, B. D., and Thompson, P. A. (2018) Celecoxib use and circulating oxylipins in a colon polyp prevention trial. PLoS One 13, e0196398

127. Birnbaum, Y., Ye, Y., Lin, Y., Freeberg, S. Y., Nishi, S. P., Martinez, J. D., Huang, M.-H., Uretsky, B. F., and Perez-Polo, J. R. (2006) Augmentation of Myocardial Production of 15-Epi-LipoxinA4 by Pioglitazone and Atorvastatin in the Rat. Circulation 114, 929-935

128. Gottschall, H., Schmöcker, C., Hartmann, D., Rohwer, N., Rund, K., Kutzner, L., Nolte, F., Ostermann, A. I., Schebb, N. H., and Weylandt, K. H. (2018) Aspirin alone and combined with a statin suppresses eicosanoid formation in human colon tissue. J. Lipid Res. 59, 864-871

129. Jesmond, D., Chiang, N., and Charles, S. (2015) Elucidation of novel 13-series resolvins that increase with atorvastatin and clear infections. Nat Med. 21, 1071-1107

130. L, L. (2003) Statins stimulate arachidonic acid release and prostaglandin 12 production in rat liver cells. Lipids in Health and Disease

131. Snowden, S. G., Grapov, D., Settergren, M., D'Alexandri, F. L., Haeggstrom, J. Z., Fiehn, O., Hyotylainen, T., Pedersen, T. L., Newman, J. W., Oresic, M., Pernow, J., and Wheelock, C. E. (2014) High-dose simvastatin exhibits enhanced lipid-lowering effects relative to simvastatin/ezetimibe combination therapy. Circ Cardiovasc Genet 7, 955-964 
132. Apaya, M. K., Chang, M.-T., and Shyur, L.-F. (2016) Phytomedicine polypharmacology: Cancer therapy through modulating the tumor microenvironment and oxylipin dynamics. Pharmacology \& Therapeutics 162 58-68

133. Mitjavila, M. T., and Moreno, J. J. (2012) The effects of polyphenols on oxidative stress and the arachidonic acid cascade. Implications for the prevention/treatment of high prevalence diseases. Biochemical Pharmacology 84 1113-1122

134. de la Puerta, R., Ruiz Gutierrez, V., and Hoult, J. R. (1999) Inhibition of leukocyte 5lipoxygenase by phenolics from virgin olive oil. Biochem Pharmacol 57, 445-449

135. Beauchamp, G. K., Keast, R. S., Morel, D., Lin, J., Pika, J., Han, Q., Lee, C. H., Smith, A. B., and Breslin, P. A. (2005) Phytochemistry: ibuprofen-like activity in extra-virgin olive oil. Nature 437, 45-46

136. Steuck, M., Hellhake, S., and Schebb, N. H. (2016) Food Polyphenol Apigenin Inhibits the Cytochrome P450 Monoxygenase Branch of the Arachidonic Acid Cascade. J Agric Food Chem 64, 8973-8976

137. Willenberg, I., Meschede, A. K., Gueler, F., Jang, M. S., Shushakova, N., and Schebb, N. H. (2015) Food Polyphenols Fail to Cause a Biologically Relevant Reduction of COX-2 Activity. PLoS One 10, e0139147

138. Schramm, D. D., Wang, J. F., Holt, R. R., Ensunsa, J. L., Gonsalves, J. L., Lazarus, S. A., Schmitz, H. H., German, J. B., and Keen, C. L. (2001) Chocolate procyanidins decrease the leukotrieneprostacyclin ratio in humans and human aortic endothelial cells. Am J Clin Nutr 73, 36-40

139. Visioli, F., Caruso, D., Grande, S., Bosisio, R., Villa, M., Galli, G., Sirtori, C., and Galli, C. (2005) Virgin Olive Oil Study (VOLOS): vasoprotective potential of extra virgin olive oil in mildly dyslipidemic patients. Eur J Nutr 44, 121-127

140. Agrawal, K., Melliou, E., Li, X., Pedersen, T. L., Wang, S. C., Magiatis, P., Newmana, J. W., and Holt, R. R. (2017) Oleocanthal-rich extra virgin olive oil demonstrates acute anti-platelet effects in healthy men in a randomized trial. Journal of Functional Foods 36, 84-93

141. Benowitz, N. L., Fitzerald, G. A., Wilson, M., and Zhang, Q. (1993) Nicotine Effects on Eicosanoid Formation and Hemostatic Function : Comparison of Transdermal Nicotine and Cigarette Smoking. J Am Coll Cardiol 22, 1159-1167

142. Saareks, V., P, Y., J, A., I, M., and A, R. (2001) Effects of smoking cessation and nicotine substitution on systemic eicosanoid production in man. Arch Pharmacol. 363, 556-561

143. Puri, P., Xu, J., Vihervaara, T., Katainen, R., Ekroos, K., Daita, K., Min, H.-K., Joyce, A., Mirshahi, F., sukamoto, H. T., and Sanyal, A. J. (2016) Alcohol produces distinct hepatic lipidome and eicosanoid signature in lean and obese. J. Lipid Res. 57, 1017-1028

144. Capó, X., Martorell, M., Sureda, A., Tur, J. A., and Pons, A. (2016 ) Effects of dietary Docosahexaenoic, training and acute exercise on lipid mediators. Journal of the International Society of Sports Nutrition 13

145. Williamson, S., Varma, D., Brown, M., and Jansen, S. (2011) Eicosanoid Production following One Bout of Exercise in Middle-Aged African American Pre- and Stage 1 Hypertensives. Journal of Aging Research 2011, 7

146. Caligiuri, S. P. B., Parikh, M., Stamenkovic, A., Pierce, G. N., and Aukema, H. M. (2017) Dietary modulation of oxylipins in cardiovascular disease and aging. Am J Physiol Heart Circ Physiol 313, H903-H918

147. Pace, S., Sautebin, L., and Werz, O. (2017) Sex-biased eicosanoid biology: Impact for sex differences in inflammation and consequences for pharmacotherapy. Biochemical Pharmacology 145 1-11

148. Picklo, M. J., Sr., and Newman, J. W. (2015) Antioxidant supplementation and obesity have independent effects on hepatic oxylipin profiles in insulin-resistant, obesity-prone rats. Free Radic Biol Med 89, 182-191

149. Shahabi, P., Siest, G., Meyer, U. A., and Visvikis-Siest, S. (2014) Human cytochrome P450 epoxygenases: Variability in expression and role in inflammation-related disorders. Pharmacology \& Therapeutics 144 134-161 
150. Cui, H., Kong, Y., and Zhang, H. (2012) Oxidative Stress, Mitochondrial Dysfunction, and Aging. Journal of Signal Transduction, 13

151. Korbecki, J., Bara nowska-Bosiacka, I., Gutowska, I., and Chlubek, D. ( 2013) The effect of reactive oxygen species on the synthesis of prostanoids from arachidonic acid. Journal of Physiology and Pharmacology 64, 409-421

152. Monsen, E. R., Okey, R., and Lyman, R. L. (1962) Effect of diet and sex on the relative lipid composition of plasma and red blood cells in the rat. Metabolism 11 1113-1124

153. Chang, T. K. H., and Waxman, D. J. (2012) Sex Differences in Drug Metabolism. In Encyclopedia of Drug Metabolism and Interactions

154. Yang, Y. M., Sun, D., Kandhi, S., Froogh, G., Zhuge, J., Huang, W., Hammock, B. D., and Huang, A. (2018) Estrogen-dependent epigenetic regulation of soluble epoxide hydrolase via DNA methylation. Proc Natl Acad Sci U S A 115, 613-618

155. Leng, S., Winter, T., and Aukema, H. M. (2018) Dietary ALA, EPA and DHA have distinct effects on oxylipin profiles in female and male rat kidney, liver and serum. J Nutr Biochem 57, 228237

156. Mendonca, A. M., Cayer, L. G. J., Pauls, S. D., Winter, T., Leng, S., Taylor, C. G., Zahradka, P., and Aukema, H. M. (2018) Distinct effects of dietary ALA, EPA and DHA on rat adipose oxylipins vary by depot location and sex. Prostaglandins Leukot Essent Fatty Acids 129, 13-24

157. Ross, S., Eikelboom, J., Anand, S. S., Eriksson, N., Gerstein, H. C., Mehta, S., Connolly, S. J., Rose, L., Ridker, P. M., Wallentin, L., Chasman, D. I., Yusuf, S., and Pare, G. (2014) Association of cyclooxygenase-2 genetic variant with cardiovascular disease. European Heart Journal 35, 2242-2248

158. Anders, G., S., N. M., Lundbye-Christensen, S., Tjønneland, A., Schmidt, E. B., and Overvad, K. ( 2016) Common Polymorphisms in the 5-Lipoxygenase Pathway and Risk of Incident Myocardial Infarction: A Danish Case-Cohort Study. PLOS ONE 11

159. Stephensen , C. B., Armstrong , P., Newman , J. W., Pedersen , T. L., Legault , J., Schuster , G. U., Kelley , D., Vikman , S., Hartiala , J., Nassir , R., Seldin , M. F., and Allayee, H. (2011 ) ALOX5 gene variants affect eicosanoid production and response to fi sh oil supplementation. J. Lipid Res. 52, 991-1003

160. Kleinstein, S. E., Heath, L., Makar, K. W., Poole, E. M., Seufert, B. L., Slattery, M. L., Xiao, L., Duggan, D. J., Hsu, L., Curtin, K., Koepl, L., Muehling, J., Taverna, D., Caan, B. J., Carlson, C. S., Potter, J. D., and Ulrich, C. M. (2013) Genetic variation in the lipoxygenase pathway and risk of colorectal neoplasia. Genes Chromosomes Cancer 52, 437-449

161. Batchu, S. N., Lee, S. B., Qadhi, R. S., Chaudhary, K. R., El-Sikhry, H., Kodela, R., Falck, J. R., and Seubert, J. M. (2011) Cardioprotective effect of a dual acting epoxyeicosatrienoic acid analogue towards ischaemia reperfusion injury. Br J Pharmacol 162, 897-907

162. Zordoky, B. N. M., and El-Kadi, A. O. S. (2010) Effect of cytochrome P450 polymorphism on arachidonic acid metabolism and their impact on cardiovascular diseases. Pharmacology \& Therapeutics 125 446-463

163. Luo, X. H., Li, G. R., and Li, H. Y. (2015) Association of the CYP4F2 rs2108622 genetic polymorphism with hypertension: a meta-analysis. Genet Mol Res 14, 15133-15139

164. Fornage, M., Lee, C. R., Doris, P. A., Bray, M. S., Gerardo, H., Zeldin, D. C., and Boerwinkle, E. (2005) The soluble epoxide hydrolase gene harbors sequence variation associated with susceptibility to and protection from incident ischemic stroke. Human Molecular Genetics 14, 2829-2837

165. Lee, C. R., North, K. E., Bray, M. S., Fornage, M., Seubert, J. M., Newman, J., Hammock, B. D., Couper, D. J., Heiss, G., and Zeldin, D. C. (2006) Genetic variation in soluble epoxide hydrolase (EPHX2) and risk of coronary heart disease: The Atherosclerosis Risk in Communities (ARIC) study. Hum Mol Genet 15, 1640-1649

166. Horn, T., Kakularamb, K. R., Anton, M., Richter, C., Reddanna, P., and Hartmut, K. (2013) Functionalcharacterizationofgeneticenzymevariations in humanlipoxygenases. RedoxBiology 1, 566-577 
167. Kunkel, G., Nigam, S., Herold, D., Jusuf, L., and Albright, D. L. (1988) Arachidonic acid metabolites and their circadian rhythm in patients with allergic bronchial asthma. Chronobiol Int 5, 387-394

168. Gooley, J. J., and Chua, E. C. (2014) Diurnal regulation of lipid metabolism and applications of circadian lipidomics. J Genet Genomics 41, 231-250

169. Dreisbach, A. W., Rice, J. C., Japa, S., Newman, J. W., Sigel, A., Gill, R. S., Hess, A. E., Cemo, A. C., Fonseca, J. P., Hammock, B. D., Lertora, J. J., and Hamm, L. L. (2008) Salt loading increases urinary excretion of linoleic acid diols and triols in healthy human subjects. Hypertension $\mathbf{5 1}$, 755-761

170. Elijovich, F., Milne, G. L., Brown, N. J., Laniado-Schwartzman, M., and Laffer, C. L. (2018) Two Pools of Epoxyeicosatrienoic Acids in Humans: Alterations in Salt-Sensitive Normotensive Subjects. Hypertension 71, 346-355

171. Cuppen, B. V., Fu, J., van Wietmarschen, H. A., Harms, A. C., Koval, S., Marijnissen, A. C., Peeters, J. J., Bijlsma, J. W., Tekstra, J., van Laar, J. M., Hankemeier, T., Lafeber, F. P., van der Greef, J., and all Society for Rheumatology Research Utrecht, i. (2016) Exploring the Inflammatory Metabolomic Profile to Predict Response to TNF-alpha Inhibitors in Rheumatoid Arthritis. PLoS One 11, e0163087

172. Zhang, Y., Guallar, E., Blasco-Colmenares, E., Harms, A. C., Vreeken, R. J., Hankemeier, T., Tomaselli, G. F., and Cheng, A. (2016) Serum-Based Oxylipins Are Associated with Outcomes in Primary Prevention Implantable Cardioverter Defibrillator Patients. PLoS One 11, e0157035

173. Gouveia-Figueira, S., Nording, M. L., Gaida, J. E., Forsgren, S., Alfredson, H., and Fowler, C. J. (2015) Serum levels of oxylipins in achilles tendinopathy: an exploratory study. PLoS One 10, e0123114

174. Loomba, R., Quehenberger, O., Armando, A., and Dennis, E. A. (2015) Polyunsaturated fatty acid metabolites as novel lipidomic biomarkers for noninvasive diagnosis of nonalcoholic steatohepatitis. J Lipid Res 56, 185-192

175. Kuc, S., Koster, M. P., Pennings, J. L., Hankemeier, T., Berger, R., Harms, A. C., Dane, A. D., Schielen, P. C., Visser, G. H., and Vreeken, R. J. (2014) Metabolomics profiling for identification of novel potential markers in early prediction of preeclampsia. PLoS One $\mathbf{9}$, e98540

176. Pickens, C. A., Sordillo, L. M., Comstock, S. S., Harris, W. S., Hortos, K., Kovan, B., and Fenton, J. I. (2015) Plasma phospholipids, non-esterified plasma polyunsaturated fatty acids and oxylipids are associated with BMI. Prostaglandins Leukot Essent Fatty Acids 95, 31-40

177. Gouveia-Figueira, S., Karimpour, M., Bosson, J. A., Blomberg, A., Unosson, J., Sehlstedt, M., Pourazar, J., Sandstrom, T., Behndig, A. F., and Nording, M. L. (2018) Mass spectrometry profiling reveals altered plasma levels of monohydroxy fatty acids and related lipids in healthy humans after controlled exposure to biodiesel exhaust. Anal Chim Acta 1018, 62-69

178. Moller, K., Ostermann, A. I., Rund, K., Thoms, S., Blume, C., Stahl, F., Hahn, A., Schebb, N. H., and Schuchardt, J. P. (2016) Influence of weight reduction on blood levels of C-reactive protein, tumor necrosis factor-alpha, interleukin-6, and oxylipins in obese subjects. Prostaglandins Leukot Essent Fatty Acids 106, 39-49

179. Gouveia-Figueira, S., Spath, J., Zivkovic, A. M., and Nording, M. L. (2015) Profiling the Oxylipin and Endocannabinoid Metabolome by UPLC-ESI-MS/MS in Human Plasma to Monitor Postprandial Inflammation. PLoS One 10, e0132042

180. R, A., AH, K., JW, N., and JC, R. (2014) The Postprandial Effects of a Moderately High-Fat Meal on Lipid Profiles and Vascular Inflammation in Alzheimer's Disease Patients: A Pilot Study. Journal of general practice 2

181. Schmocker, C., Zhang, I. W., Kiesler, S., Kassner, U., Ostermann, A. I., Steinhagen-Thiessen, E., Schebb, N. H., and Weylandt, K. H. (2018) Effect of Omega-3 Fatty Acid Supplementation on Oxylipins in a Routine Clinical Setting. Int J Mol Sci 19 
182. Schuchardt, J. P., Ostermann, A. I., Stork, L., Fritzsch, S., Kohrs, H., Greupner, T., Hahn, A., and Schebb, N. H. (2017) Effect of DHA supplementation on oxylipin levels in plasma and immune cell stimulated blood. Prostaglandins Leukot Essent Fatty Acids 121, 76-87

183. Watkins, B. A., Kim, J., Kenny, A., Pedersen, T. L., Pappan, K. L., and Newman, J. W. (2016) Circulating levels of endocannabinoids and oxylipins altered by dietary lipids in older women are likely associated with previously identified gene targets. Biochim Biophys Acta 1861, 1693-1704

184. Holt, R. R., Yim, S. J., Shearer, G. C., Hackman, R. M., Djurica, D., Newman, J. W., Shindel, A. W., and Keen, C. L. (2015) Effects of short-term walnut consumption on human microvascular function and its relationship to plasma epoxide content. J Nutr Biochem 26, 1458-1466

185. Kutzner, L., Rund, K. M., Ostermann, A. I., Hartung, N. M., Galano, J. M., Balas, L., Durand, T., Balzer, M. S., David, S., and Schebb, N. H. (2019) Development of an Optimized LC-MS Method for the Detection of Specialized Pro-Resolving Mediators in Biological Samples. Front Pharmacol 10, 169

186. Deems, R., Buczynski, M. W., Bowers-Gentry, R., Harkewicz, R., and Dennis, E. A. (2007) Detection and quantitation of eicosanoids via high performance liquid chromatographyelectrospray ionization-mass spectrometry. Methods Enzymol 432, 59-82

187. Quehenberger, O., Armando, A. M., Brown, A. H., Milne, S. B., Myers, D. S., Merrill, A. H., Bandyopadhyay, S., Jones, K. N., Kelly, S., Shaner, R. L., Sullards, C. M., Wang, E., Murphy, R. C., Barkley, R. M., Leiker, T. J., Raetz, C. R., Guan, Z., Laird, G. M., Six, D. A., Russell, D. W., McDonald, J. G., Subramaniam, S., Fahy, E., and Dennis, E. A. (2010) Lipidomics reveals a remarkable diversity of lipids in human plasma. J Lipid Res 51, 3299-3305

188. Quehenberger, O., Yamashita, T., Armando, A. M., Dennis, E. A., and Palinski, W. (2011) Effect of gestational hypercholesterolemia and maternal immunization on offspring plasma eicosanoids. Am J Obstet Gynecol 205, 156 e115-125

189. Wang, Y., Armando, A. M., Quehenberger, O., Yan, C., and Dennis, E. A. (2014) Comprehensive ultra-performance liquid chromatographic separation and mass spectrometric analysis of eicosanoid metabolites in human samples. J Chromatogr A 1359, 60-69

190. Kortz, L., Dorow, J., Becker, S., Thiery, J., and Ceglarek, U. (2013) Fast liquid chromatographyquadrupole linear ion trap-mass spectrometry analysis of polyunsaturated fatty acids and eicosanoids in human plasma. J Chromatogr B Analyt Technol Biomed Life Sci 927, 209-213

191. Colas, R. A., Shinohara, M., Dalli, J., Chiang, N., and Serhan, C. N. (2014) Identification and signature profiles for pro-resolving and inflammatory lipid mediators in human tissue. Am J Physiol Cell Physiol 307, C39-54

192. Dalli, J., Colas, R. A., Walker, M. E., and Serhan, C. N. (2018) Lipid Mediator Metabolomics Via LC-MS/MS Profiling and Analysis. Methods Mol Biol 1730, 59-72

193. Yuan, Z. X., Majchrzak-Hong, S., Keyes, G. S., ladarola, M. J., Mannes, A. J., and Ramsden, C. E. (2018) Lipidomic profiling of targeted oxylipins with ultra-performance liquid chromatography-tandem mass spectrometry. Anal Bioanal Chem 410, 6009-6029

194. Song, J., Liu, X., Wu, J., Meehan, M. J., Blevitt, J. M., Dorrestein, P. C., and Milla, M. E. (2013) A highly efficient, high-throughput lipidomics platform for the quantitative detection of eicosanoids in human whole blood. Anal Biochem 433, 181-188

195. Massey, K. A., and Nicolaou, A. (2013) Lipidomics of oxidized polyunsaturated fatty acids. Free Radic Biol Med 59, 45-55

196. Astarita, G., McKenzie, J. H., Wang, B., Strassburg, K., Doneanu, A., Johnson, J., Baker, A., Hankemeier, T., Murphy, J., Vreeken, R. J., Langridge, J., and Kang, J. X. (2014) A protective lipidomic biosignature associated with a balanced omega-6/omega-3 ratio in fat-1 transgenic mice. PLoS One 9, e96221

197. Balvers, M. G., Verhoeckx, K. C., Meijerink, J., Bijlsma, S., Rubingh, C. M., Wortelboer, H. M., and Witkamp, R. F. (2012) Time-dependent effect of in vivo inflammation on eicosanoid and 
endocannabinoid levels in plasma, liver, ileum and adipose tissue in C57BL/6 mice fed a fishoil diet. Int Immunopharmacol 13, 204-214

198. Zhang, X., Yang, N., Ai, D., and Zhu, Y. (2015) Systematic metabolomic analysis of eicosanoids after omega-3 polyunsaturated fatty acid supplementation by a highly specific liquid chromatography-tandem mass spectrometry-based method. J Proteome Res 14, 1843-1853

199. Lee, Y. Y., and Lee, J. C. (2018) LC-MS/MS Analysis of Lipid Oxidation Products in Blood and Tissue Samples. Methods Mol Biol 1730, 83-92

200. Bauer, J., Ripperger, A., Frantz, S., Ergun, S., Schwedhelm, E., and Benndorf, R. A. (2014) Pathophysiology of isoprostanes in the cardiovascular system: implications of isoprostanemediated thromboxane A2 receptor activation. Br J Pharmacol 171, 3115-3131

201. Dennis, E. A., and Norris, P. C. (2015) Eicosanoid storm in infection and inflammation. Nat Rev Immunol 15, 511-523

202. Gabbs, M., Leng, S., Devassy, J. G., Monirujjaman, M., and Aukema, H. M. (2015) Advances in Our Understanding of Oxylipins Derived from Dietary PUFAs. Adv Nutr 6, 513-540

203. Milne, G. L., Dai, Q., and Roberts, L. J., 2nd. (2015) The isoprostanes--25 years later. Biochim Biophys Acta 1851, 433-445

204. Waldman, M., Peterson, S. J., Arad, M., and Hochhauser, E. (2016) The role of 20-HETE in cardiovascular diseases and its risk factors. Prostaglandins Other Lipid Mediat 125, 108-117 
Highlights

1. Oxylipin signatures can provide biomarkers of disease, diet and drug effects.

2. Expansive oxylipin coverage is essential for integrative biological interpretation.

3. Targeted metabolomics of oxylipins has to be standardized.

4. The natural variance of oxylipin biosynthesis has to be assessed. 